\title{
A novel human leiomyoma tissue derived matrix for cell culture studies
}

Tuula Salo ${ }^{1,2,3^{*}}$, Meeri Sutinen ${ }^{1,2}$, Ehsanul Hoque Apu ${ }^{1,2}$, Elias Sundquist ${ }^{1,2}$, Nilva K. Cervigne ${ }^{4,5}$, Carine Ervolino de Oliveira ${ }^{5}$, Saad Ullah Akram ${ }^{6,7}$, Steffen Ohlmeier ${ }^{8,9}$, Fumi Suomi ${ }^{7,8}$, Lauri Eklund ${ }^{7,8}$, Pirjo Juusela ${ }^{3}$, Pirjo Åström ${ }^{1,2}$, Carolina Cavalcante Bitu ${ }^{1,2}$, Markku Santala ${ }^{10}$, Kalle Savolainen ${ }^{11}$, Johanna Korvala ${ }^{1,2}$,

Adriana Franco Paes Leme ${ }^{12}$ and Ricardo D. Coletta ${ }^{5}$

\begin{abstract}
Background: The composition of the matrix molecules is important in in vitro cell culture experiments of e.g. human cancer invasion and vessel formation. Currently, the mouse Engelbreth-Holm-Swarm (EHS) sarcoma -derived products, such as Matrigel ${ }^{\oplus}$, are the most commonly used tumor microenvironment (TME) mimicking matrices for experimental studies. However, since Matrige ${ }^{\circledast}$ is non-human in origin, its molecular composition does not accurately simulate human TME. We have previously described a solid 3D organotypic myoma disc invasion assay, which is derived from human uterus benign leiomyoma tumor. Here, we describe the preparation and analyses of a processed, gelatinous leiomyoma matrix, named Myogel.
\end{abstract}

Methods: A total protein extract, Myogel, was formulated from myoma. The protein contents of Myogel were characterized and its composition and properties compared with a commercial mouse Matrige ${ }^{\oplus}$. Myogel was tested and compared to Matrige ${ }^{\circledR}$ in human cell adhesion, migration, invasion, colony formation, spheroid culture and vessel formation experiments, as well as in a 3D hanging drop video image analysis.

Results: We demonstrated that only $34 \%$ of Myogel's molecular content was similar to Matrigel ${ }^{\oplus}$. All test results showed that Myogel was comparable with Matrigel ${ }^{\oplus}$, and when mixed with low-melting agarose (Myogel-LMA) it

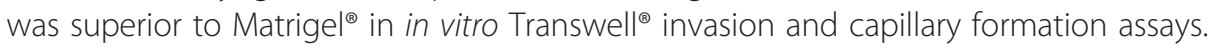

Conclusions: In conclusion, we have developed a novel Myogel TME matrix, which is recommended for in vitro human cell culture experiments since it closely mimics the human tumor microenvironment of solid cancers.

Keywords: Tumor microenvironment matrix, Invasion, Migration, Hanging drop, Colony formation, Spheroid formation, Capillary formation

\section{Background}

Translational cancer research almost completely lacks human tissue in vitro models that mimic the natural tumor microenvironment matrix (TMEM). This also was partially fulfilled by our organotypic leiomyoma 3D solid disc model [1], which has been successfully used in numerous cancer invasion studies [2-7]. In this model, the hypoxic tumor matrix provides an authentic environment

\footnotetext{
* Correspondence: tuula.salo@oulu.fi

'Cancer and Translational Medicine Research Unit, Faculty of Medicine, University of Oulu, PO Box 5281FI-90014 Oulu, Finland

${ }^{2}$ Medical Research Center Oulu, Oulu University Hospital and University of Oulu, Fl-90014 Oulu, Finland

Full list of author information is available at the end of the article
}

including e.g. fibroblasts, vessels, collagen fibers, laminins, glycoproteins, cytokines and proteases [8].

Matrigel $^{\circ}$ (BD Biosciences), the mouse EngelbrethHolm-Swarm (EHS) tumor-derived commercial product [9], is widely used for in vitro adhesion, invasion and capillary formation assays $[10,11]$. However, the tumor matrix of rodents clearly differs from the respective human TMEM [12]. These differences most likely affect human cancer invasion processes and underscore the need for soluble human TMEM products. In addition to classic Matrigel $^{\circ}$ other EHS tumor derived products are also available, such as ECM gel (Sigma), Cultrex BME (Amsbio), Geltrex (Gibco Life Technologies) and ECMatrix $^{\mathrm{Tm}}$ (Millipore). All these products have the same 
disadvantage for human studies; they are mouse tumor tissue homogenates that differ in composition from human TMEM.

Since collagens are the most abundant proteins in the extracellular matrix (ECM), gels from purified rodent collagens are commonly used to embed cells into 3D cultures $[13,14]$. In organotypic 3D cultures, type I collagen derived from rat tail is probably the most abundant ECM mimicking matrix. Other commercially available ECM molecules, like fibronectin [15], fibrin [16] and hyaluronic acid [17], are also used for in vitro studies. In addition, synthetic ECM or peptide matrices are available from various manufacturers. However, one purified molecule, a mixture of them, or totally synthetic matrices do not adequately simulate the complex effects of natural ECM due to the obvious lack of hundreds of cytokines or protease cleavage sites identified in natural tumor ECM [18, 19]. Moreover, the excessive presence of one molecule or a mixture of basement membrane components rich in growth factors does not reflect the ECM composition synthesized by stromal cells. In vivo the combinations of multiple TMEM factors are important for cell-ECM interactions during cancer progression [20].

Three recent reports [21-23] use the term myogel for an extracellular matrix material that is derived from human, mouse, rat or pig normal skeletal muscles using procedures similar to those of Kibbey [9] for the preparation of EHS tumor extract. The myogel material was shown to be adipogenic $[21,23]$ and to support the $e x$ vivo amplification of corneal epithelial cells [22]. Vivo Biosciences Inc. is marketing HuBiogel, an ECM gel derived from normal human amnion tissue containing laminin, collagen types I and IV, entactin, tenascin and heparan sulfate proteoglycan, but lacking endogenous growth factors (EGF, TGF- $\alpha$, TGF- $\beta$, FGF and PDGF) as well as MMP-2 and MMP-9 [24]. These commercial products and other human ECM matrices used in research are derived from normal tissues (skeletal muscle, amnion membrane, placenta) or are in vitro, cell culture -derived [MaxGel ${ }^{\mathrm{mm}}$ Human ECM (Sigma), AlphaMAX3D (Neuromics)].

Here we describe a novel product prepared from human uterus benign leiomyoma tumor tissue [1] according to the method described for the preparation of Matrigel $^{\bullet}$ [9]. We formulated a solution/gel of the total protein extracts, characterized the protein contents, and compared with Matrigel $^{\circ}$ using a set of in vitro experiments. Based on the results we conclude that the tumor tissue solution/gel derived from human leiomyoma offers an excellent human TMEM tool for analyzing human carcinoma cells in vitro. This novel Myogel product, combined with low melting agarose (LMA), provides an accessible method for analyzing cancer cell invasive, adhesive or migratory properties; potential chemotherapeutic compounds; as well as to test capillary formation. Hence Myogel-LMA together with myoma discs could offer a practical human "TMEM tissue kit" for translational cancer research purposes.

\section{Methods \\ Myogel preparation}

Human uterus leiomyoma tissue (after taking samples for histopathological analyses) was received from the Oulu University Hospital, Department of Gynecology [1] and the Tampere University Hospital, Department of Gynecology after obtaining the patients' written informed consent. The use of myoma tissue was approved by the Ethics Committee of both the Oulu University Hospital, and the Tampere University Hospital. Myogel was prepared according to the method described [9] for the preparation of EHS sarcoma derived Matrigel $^{\circ}$ (BD Biosciences), with minor modifications. Briefly, myoma tissue, frozen with liquid nitrogen, was ground to a powder with a CryoMill (Retsch, Haan, Germany), and $10 \mathrm{~g}$ of tissue powder was suspended in $20 \mathrm{ml}$ of ice cold 3.4 M, pH 7.4 NaCl buffer. After centrifugation, the pellet was homogenized in another $20 \mathrm{ml}$ of the same $\mathrm{NaCl}$ buffer using a T18 Ultra-Turrax (IKA ${ }^{\circ}$-Werke GmbH \& Co. KG, Staufen, Germany). A T18 Ultra-Turrax was also used in all the following homogenizations. The protein concentration in each preparation was measured using a DC Protein Assay (Bio-Rad) according to the manufacturer's instructions. The absorbance at $590 \mathrm{~nm}$ was measured using a Victor ${ }^{3} \mathrm{~V} 1420$ Multilabel Counter and Wallac 1420 Manager (Perkin Elmer Life and Analytical Sciences, Turku, Finland). The protein concentrations in various Myogel batches were diluted using cell culture media described in the cell culture -section (see below) to match those of Matrigel ${ }^{\circ}$. The Myogel solution was then stored in small $(\leq 1 \mathrm{ml})$ aliquots at $-20{ }^{\circ} \mathrm{C}$.

\section{Gradient SDS-PAGE of Myogel and Matrige $^{\circledR}$ and proteomic analyses of Myogel}

Samples $(20 \mu \mathrm{g})$ of four different Myogel batches (preparation numbers 12, 15, 16 and 17) and their mixture, as well as four different Matrigel $^{\circ}$ (BD Matrigel Matrix, BD Biosciences, Cat. Number 354234) samples were loaded on a gradient $(4 \%, 8 \%, 15 \%)$ SDS-PAGE gel and separated using $15 \mathrm{~mA}$ for $90 \mathrm{~min}$. A PageRuler Plus Prestained Protein Ladder (Thermo Scientific) was used as a molecular weight marker. Proteins were stained using Coomassie Blue and the gel was washed with elution buffer to remove excess staining. The gel was photographed over a stripping table.

For proteomic analysis, $10 \mu \mathrm{g}$ and $20 \mu \mathrm{g}$ of four different Myogel batches (preparation numbers 3, 4, 6, 9) were separated as above. The gel was viewed over a stripping table, and individual bands were cut and 
collected from the gel. After digestion $(0.3 \mu \mathrm{g}$ of trypsin was used/band) each band was resuspended with formic acid (see $\mu \mathrm{l} /$ band in the Additional file 1: Figure S1B) on three selected Myogel samples (preparations 3, 6, 9) and stored in $-20{ }^{\circ} \mathrm{C}$ until gel digestion for mass spectrometry. The gel digestion of selected samples for mass spectrometry was done according to Hanna et al. [25] with some modifications.

\section{Mass spectrometry analysis}

An aliquot of $4.5 \mu \mathrm{l}$ of the resulting peptide mixture was analyzed on an ETD-enabled LTQ Orbitrap Velos mass spectrometer (Thermo Fisher Scientific, Waltham, MA) connected to a nanoflow liquid chromatography (LCMS/MS) instrument by an EASY-nLC system (Proxeon Biosystems, West Palm Beach, FL) with a Proxeon nanoelectrospray ion source. Peptides were separated with a $2-90 \%$ acetonitrile gradient in $0.1 \%$ formic acid using an analytical column PicoFrit Column $(20 \mathrm{~cm} x$ ID75 $\mu \mathrm{m}, 5 \mu \mathrm{m}$ particle size, New Objective, Woburn, MA) at a flow of $300 \mathrm{nl} / \mathrm{min}$ over $27 \mathrm{~min}$. The nanoelectrospray voltage was set to $2.2 \mathrm{kV}$ and the source temperature was $275{ }^{\circ} \mathrm{C}$. All of the instrument methods were set up in the data-dependent acquisition mode. The full scan MS spectra (m/z 300-1600) were acquired in the Orbitrap analyzer after accumulation to a target value of $10^{6}$. The resolution in the Orbitrap was set to $r$ $=60,000$ and the 20 most intense peptide ions with charge states $\geq 2$ were sequentially isolated to a target value of 5000 and fragmented in the linear ion trap using low-energy CID (normalized collision energy of $35 \%)$. The signal threshold for triggering an MS/MS event was set to 1000 counts. Dynamic exclusion was enabled with an exclusion size list of 500, exclusion duration of $60 \mathrm{~s}$, and a repeat count of 1 . An activation $\mathrm{q}=$ 0.25 and activation time of $10 \mathrm{~ms}$ were used.

\section{Data analysis}

Peak lists (msf) were generated from the raw data files using the Proteome Discoverer software version 1.3.0.339 (Thermo Fisher Scientific) with the Sequest search engine and searched against the UniProt Human Protein Database (release July 11, 2012; 69,711 entries), with the following parameters: carbamidomethylation as the fixed modification $(+57.021 \mathrm{Da})$, oxidation of methionine $(+15.995 \mathrm{Da})$ as the variable modification, one trypsin missed cleavage and a tolerance of $10 \mathrm{ppm}$ for precursor and $1 \mathrm{Da}$ for fragment ions. All datasets were processed using the workflow feature in the Proteome Discoverer software, and the resulting search data were further analyzed in the software ScaffoldQ + v.3.3.1 (Proteome Software, Inc.). The scoring parameters (Xcorr and Peptide Probability) in the ScaffoldQ+ software were set to obtain a false discovery rate (FDR) of less than $1 \%$, using the number of total spectra output from the ScaffoldQ+ software, strict parsimony principle was enabled, and leucine and isoleucine were considered equal. A normalization criterion, the quantitative value, was applied to the spectral counts.

\section{Two-Dimensional Gel Electrophoresis (2-DE)}

For the proteomic analyses two Myogel and one Matrigel $^{\circ}$ (BD Matrigel Matrix, BD Biosciences, Cat. Number 354234) samples were further purified by buffer exchange using an Amicon Ultra ultrafiltration unit with a $10 \mathrm{kDa}$ cutoff (Millipore) and urea buffer (7 M urea, $2 \mathrm{M}$ thiourea, $4 \%$ [w/v] CHAPS, $30 \mathrm{mM}$ Tris, $\mathrm{pH} 8.5$ ). After that the protein samples were sonicated and centrifuged. The protein concentrations in the supernatants were determined in duplicate with a Bradford-based assay according to the manufacturer's instructions (Roti ${ }^{\circ}$-Nanoquant, Carl Roth) with urea buffer as a control and aliquots were stored at $-20{ }^{\circ} \mathrm{C}$. For 2-DE, $100 \mu \mathrm{g}$ of the protein solution of each sample was adjusted with rehydration urea buffer $(7 \mathrm{M}$ urea, $2 \mathrm{M}$ thiourea, $4 \%[\mathrm{w} / \mathrm{v}$ ] CHAPS, $0.15 \%$ [w/v] DTT, $0.5 \%$ [v/v] carrier ampholytes 3-10, Complete Mini protease inhibitor cocktail (Roche)) to a final volume of $400 \mu$ l. In-gel rehydration with IPG strips (pH 4-7, $18 \mathrm{~cm}$, GE Healthcare) was performed overnight. Isoelectric focusing (IEF) was carried out with the Multiphor II system (GE Healthcare) under paraffin oil for $55 \mathrm{kVh}$. SDS-PAGE was performed overnight in polyacrylamide gels $(12.5 \% \mathrm{~T}, 2.6 \% \mathrm{C})$ with the Ettan DALT II system (GE Healthcare) at $1-2 \mathrm{~W}$ per gel and $12{ }^{\circ} \mathrm{C}$. The gels were silver stained as described by Ohlmeier et al. [26] and analyzed with the 2-D PAGE image analysis software Melanie 3.0 (GeneBio).

\section{Zymography}

Gelatinolytic enzymes in Myogel and Matrigel $^{\circ}$ (BD Matrigel Matrix, BD Biosciences, Cat. Number 354234) were detected by a zymography method using fluorescently labeled gelatin [27]. Prestained low-range SDSPAGE Standards (Bio-Rad) as well as purified control MMP-2 and MMP -9 samples were loaded in adjacent wells. After electrophoresis, gelatinases were activated by incubating the gels with zymography buffer $(50 \mathrm{mM}$ Tris-HCl, $5 \mathrm{mM} \mathrm{CaCl}, 1 \mu \mathrm{M} \mathrm{ZnCl}, 0.02 \% \mathrm{NaN}^{3}$, $\mathrm{pH}$ 7.5) overnight at $37^{\circ} \mathrm{C}$. Gelatin degradation was visualized under long wave UV light and photographed using an AlphaDigiDoc ${ }^{\circ}$ RT Gel Documentation System (Alpha Innotech, San Leandro, CA).

\section{Assessing the $\mathrm{pH}$ of Myogel and Matrigel ${ }^{\oplus}$}

For $\mathrm{pH}$ comparison, Matrigel ${ }^{\circ}$ (BD Matrigel Matrix, BD Biosciences, Cat. Number 354234) was diluted with an equal volume of serum free medium, and the same 
amount of total protein for Myogel was obtained by diluting it $10+6$ with serum free medium. The $\mathrm{pH}$ of both gels was measured at the beginning, after $17 \mathrm{~h}$, and at the end of the $48 \mathrm{~h}$ experiment. The gels were incubated at $37{ }^{\circ} \mathrm{C}$ in a $5 \% \mathrm{CO}_{2}$ humidified cell culture chamber with or without HSC-3 cells (see below for the culture conditions) on top of the gels.

\section{Cell lines}

Aggressive human oral tongue squamous cell carcinoma cell line HSC-3 (Japan Health Sciences Foundation, Japan) was cultured in a 1:1 DMEM/F-12 medium (Life Technologies) supplemented with $100 \mathrm{U} / \mathrm{ml}$ penicillin, $100 \mu \mathrm{g} / \mathrm{ml}$ streptomycin, $250 \mathrm{ng} / \mathrm{ml}$ fungizone, $50 \mu \mathrm{g} / \mathrm{ml}$ ascorbic acid and $0.4 \mu \mathrm{g} / \mathrm{ml}$ hydrocortisone (all from Sigma-Aldrich) and $10 \%$ heat inactivated fetal bovine serum (FBS; Life technologies). HSC-3 cells labeled with GFP were generated by stable transduction with nonsilencing GIPZ lentiviral shRNAmir control particles (pGIPZ vector contains GFP in order to track shRNAmir expression; Thermo Fischer Open Biosystems) with puromycin (Sigma-Aldrich) selection according to the manufacturer's instructions. Nuclear histone-2B (H2B)coupled mCherry expression vector pLenti6.2 V5/DEST (a gift from Dr. Cindy E. Dieteren, Department of Cell Biology, Radboud UMC, Netherlands) was introduced into the HSC-3 cells with cytosolic GFP labeling using lentivirus mediated infection and selected in culture media containing $5 \mu \mathrm{g} / \mathrm{ml}$ blasticidin-S (Merck Millipore). HSC-3 cells expressing cytoplasmic GFP and H2B-coupled mCherry were cultured in DMEM/F12 medium (Gibco/Thermo Fisher Scientific), $10 \%$ heatinactivated FBS (HyClone/Thermo Fisher Scientific), 100 $\mathrm{U} / \mathrm{ml}$ penicillin, $100 \mu \mathrm{g} / \mathrm{ml}$ streptomycin (Sigma-Aldrich), $50 \mu \mathrm{g} / \mathrm{ml} \mathrm{L}$-ascorbic acid (Sigma-Aldrich) and $2 \mathrm{mM}$ L-glutamine (Sigma-Aldrich). HSC-3 cells labeled with RFP were generated by stable transduction with commercial lentiviral particles containing a non-coding control sequence (Amsbio) and selected with puromycin. They were cultured as normal HSC-3 cells.

The SCC-9 cell line (American Type Culture Collection, ATCC) was maintained in DMEM/F-12 medium (Invitrogen) supplemented with $10 \%$ FBS (Cultilab), $400 \mathrm{ng} / \mathrm{mL}$ hydrocortisone, and antibiotic/antimycotic solution (Invitrogen). SCC-9 cells were labeled with ZsGreen protein and implanted subcutaneously into the footpads of the left front limb of BALB/c nude mice and LN-1 and LN-2 cell lines with increased metastatic potential were derived by in vivo selection from axillary lymph nodes with metastatic cells as described earlier [6]. Both LN-1 and LN-2 cells were maintained in culture as SCC-9.

Normal oral gingival fibroblasts (GF) were established from palatal gingiva mucosa biopsies and cultured in
DMEM medium (high glucose, GlutaMAX ${ }^{\mathrm{TM}}$ and pyruvate) supplemented with $10 \% \mathrm{FBS}, 50 \mathrm{U} / \mathrm{ml}$ penicillin, $50 \mu \mathrm{g} / \mathrm{ml}$ streptomycin and $2.5 \mu \mathrm{g} / \mathrm{ml}$ amphotericin B (all from Gibco). After obtaining written informed consent, the palatal tissue biopsies were taken from healthy volunteers for another study to be used as a starting material for control fibroblast cell line cultures. The volunteer consent encompassed the use of obtained cell lines for other studies as well. The use of palatal tissue was approved by the Ethics Committee of the Helsinki University Hospital. The carcinoma associated fibroblast (CAF) cell lines were generated from fragments of tongue squamous cell carcinomas by using tissue explants [28]. They were cultured in DMEM medium supplemented with $100 \mathrm{U} / \mathrm{ml}$ penicillin, $100 \mu \mathrm{g} / \mathrm{ml}$ streptomycin, $50 \mu \mathrm{g} / \mathrm{ml}$ ascorbic acid, $250 \mathrm{ng} / \mathrm{ml}$ fungizone, $1 \mathrm{mmol} / \mathrm{L}$ sodium pyruvate (Sigma-Aldrich) and $10 \%$ heat inactivated FBS.

Melanoma cell lines SK-Mel-25 and A2058 (ATCC) were maintained in RPMI medium (Invitrogen) supplemented with $10 \%$ FBS (Cultilab) as described earlier [29]. Human umbilical vein endothelial cells (HUVEC, ATCC) were cultured in a 1:1 mixture of DMEM/F12 medium (Invitrogen) supplemented with $10 \% \mathrm{FBS}$ and $400 \mathrm{ng} / \mathrm{ml}$ hydrocortisone (Sigma-Aldrich).

All the cells were cultured in a humidified atmosphere of $5 \% \mathrm{CO}_{2}$ at $37{ }^{\circ} \mathrm{C}$ and passaged routinely using trypsin-EDTA (Sigma-Aldrich). The media were changed every $2-3$ days. They were regularly tested and confirmed to be negative for mycoplasma infection using a MycoTrace PCR Detection Kit (PAA Laboratories $\mathrm{GmbH})$. Cell line identity was not routinely performed.

\section{Adhesion assay}

A cell adhesion assay was conducted to determine how many cells bind to Myogel compared to Matrigel $^{\circ}$ (BD Matrigel Matrix, BD Biosciences, Cat. Number 354234). In this assay, HSC-3 cells were cultured to subconfluence. Wells in a 96-well plate were coated for $24 \mathrm{~h}$ either with $100 \mu \mathrm{l}$ of PBS, BSA (bovine serum albumin, $10 \mu \mathrm{g} /$ $\mathrm{ml}$, Sigma-Aldrich), Matrigel $^{\circ}$ or Myogel (two different batches). Matrigel ${ }^{\circ}$ was diluted to 1:10 in PBS and Myogel was diluted to the same protein concentration. At the same time, the cell culture medium was changed to serum-free medium. The next day the excess liquids were removed and the culture plates were incubated with $100 \mu \mathrm{l} /$ well of $0.1 \%$ BSA for $2 \mathrm{~h}$ and washed with PBS. HSC-3 cells (6000) in $100 \mu$ of serum-free medium were added to each well and the wells were incubated at $37{ }^{\circ} \mathrm{C}$ in a $5 \% \mathrm{CO}_{2}$ humidified atmosphere for $2 \mathrm{~h}$. The non-adherent cells were rinsed off, and the remaining cells were fixed with $10 \%$ trichloroacetic acid (TCA), stained with crystal violet and quantified using an ELISA reader at $540 \mathrm{~nm}$. 
Adhesion of GFs on top of Myogel was studied using 6-well plates coated at $37^{\circ} \mathrm{C}$ in a $5 \% \mathrm{CO}_{2}$ humidified atmosphere with $0.62 \mathrm{mg} / \mathrm{ml}$ Myogel diluted with DMEM without supplements. After $2 \mathrm{~h}$ the excess liquids were removed and 150,000 GFs were added in their normal culture medium. The cultures were photographed with Olympus CKX41 inverted microscope (Hamburg, Germany) after $2.5 \mathrm{~h}$ and $9.5 \mathrm{~h}$ with $20 \mathrm{x}$ magnification to record the morphology of the cells.

\section{Terminal deoxynucleotidyl transferase dUTP nick end labeling (TUNEL)}

An 8-well Nunc ${ }^{\text {Tx }}$ Lab-Tek $^{\text {TM }}$ chambered slide (Thermo Scientific) was used for the experiment. Wells were coated with either rat tail collagen type I (BD Biosciences), one of three different batches of Myogel or an equal (50-50 \%) mixture of collagen type I and one type of Myogel. A total of $150 \mu \mathrm{l}$ of coating mixtures were prepared, with a final protein concentration of each gel mixture of $0.62 \mathrm{mg} / \mathrm{ml}$, which were adjusted with the addition of culture medium. Two wells were not coated and were kept for positive and negative controls for the

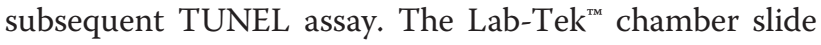
was covered and placed in the incubator at $37{ }^{\circ} \mathrm{C}$ in $5 \%$ $\mathrm{CO}_{2}$ for $2 \mathrm{~h}$. Subsequently, 5000 CAFs were added on each well and the slide placed in the incubator overnight. On the following day, the wells were washed twice with PBS, air-dried for few min and fixed with freshly prepared $4 \%(\mathrm{w} / \mathrm{v})$ paraformaldehyde in PBS ( $\mathrm{pH} 7.4$ ) for 1 hour at RT. After 2 washes with PBS for $5 \mathrm{~min}$ each, the TUNEL assay was performed using a commercially available kit (In Situ Cell Death Detection Kit, Roche). At the end of the assay, samples were counterstained with DAPI for $10 \mathrm{~min}$ at RT. After coverslip mounting with a water-based medium, 100 cells were counted under a confocal microscope using the blue channel $(405 \mathrm{~nm})$ and apoptosis was detected using the green channel (488 $\mathrm{nm})$.

\section{CAFs cultured within Myogel}

Myogel for CAF embedding was prepared as described for collagen organotypic culture in Nurmenniemi et al. [1]. Briefly, a gel mixture including 8 volumes of Myogel (4.5 $\mathrm{mg} / \mathrm{ml}), 1$ volume of $10 \times$ DMEM (Sigma Aldrich) and 1 volume of FBS with CAFs (final concentration 70,000 cells/ $400 \mu \mathrm{l}$ gel mixture) was prepared on ice and $400 \mu \mathrm{l}$ aliquots were added into the wells of a 48 well plate. After $40 \mathrm{~min}$ polymerization, $100 \mu \mathrm{l}$ of complete CAF medium was added on the polymerized gels. The plates were incubated at $37{ }^{\circ} \mathrm{C}$ in a $5 \%$ $\mathrm{CO}_{2}$ humidified atmosphere. Cells were fed twice a week and pictures were taken with an EVOS microscope (Advanced Microscopy Group, Bothell, WA) weekly for three weeks.

\section{Myogel as a supplement in soft agar colony formation -assay}

For the soft agar mimicking assay, one percent sterile base low melting agarose (LMA, Sea Plaque Low Melting Agarose, Lonza) melted in PBS was mixed with 10x DMEM/F12, $100 \%$ FBS to give a final $0.8 \%$ agarose with $1 \mathrm{x}$ medium, $10 \% \mathrm{FBS}$. One-half $\mathrm{ml}$ of the mixture was added to wells in a 24-well plate and allowed to solidify for at least $30 \mathrm{~min}$ in the laminar flow hood. 10 000 HSC-3 (H2B-GFP) cells in $50 \mu \mathrm{l}$ of FBS were mixed with $50 \mu \mathrm{l}$ of $10 \mathrm{x}$ DMEM/F12 and $0.4 \mathrm{ml}$ of $0.5 \%$ LMA (as a control, final agarose concentration $0.4 \%$ ) or with $50 \mu \mathrm{l}$ of $10 \mathrm{x}$ DMEM/F12, $0.2 \mathrm{ml}$ of $1.0 \%$ agarose and $0.2 \mathrm{ml}$ Myogel (final agarose concentration $0.4 \%$, final Myogel protein concentration $2.2 \mathrm{mg} / \mathrm{ml}$ ). Myogel was centrifuged at $4000 \mathrm{rpm}$ for $10 \mathrm{~min}$ prior to the procedure. The agarose mixture was gently mixed by swirling, and $0.5 \mathrm{ml}$ was added on the top of the agarose base. The plates were incubated at $37{ }^{\circ} \mathrm{C}$ in a $5 \% \mathrm{CO}_{2}$ humidified atmosphere for 28 days. The cells were fed twice a week with $0.25 \mathrm{ml}$ normal HSC-3 medium. Pictures of the colonies were taken with transmitted light and in the GFP \& RFP channels in different objectives (10x, 20x \& 40x) using an EVOS inverted microscope. Cells in colonies were calculated from the pictures and ImageJ software (Rasband, W.S., ImageJ, U.S. National Institutes of Health, Bethesda, Maryland, USA) was used to measure colony area.

\section{Hanging drop spheroid cultures in Myogel with low-melting agarose (Myogel-LMA)}

The spheroids were formed according to published protocol [30]. $20 \mu \mathrm{l}$ drops of the cell suspension (70,000 HSC-3 (H2B-GFP) cells per drop) suspended in DMEM/ F12 medium with $10 \%$ FBS were placed onto the lids of $10 \mathrm{~cm}$ dishes, which were inverted over dishes containing $10 \mathrm{ml}$ PBS. Hanging drop cultures were incubated for $72 \mathrm{~h}$, the resulting cellular aggregates were harvested by a pipette and embedded in two different conditions (Myogel-LMA \& LMA) into the wells of a 48- well plate as in the soft agar colony formation -assay above. After $6 \mathrm{~h}$ incubation at $37{ }^{\circ} \mathrm{C}$ in a $5 \% \mathrm{CO}_{2}$ humidified atmosphere, $150 \mu \mathrm{l}$ normal HSC-3 cell culture medium was added per well. Pictures of the spheroids were taken with $4 \mathrm{x}$ objective using an EVOS inverted microscope at $0 \mathrm{~h}, 24 \mathrm{~h}, 48 \mathrm{~h}$ and $72 \mathrm{~h}$ after embedding. ImageJ software was used to measure spheroid area and the results were calculated as a ratio to the area of the implanted spheroid right after embedding (without media).

\section{Microarray}

For microarray analysis, 90,000 HSC-3 cells transduced with RFP were seeded into uncoated or Myogel coated 6-well plates (three wells each). The next day the cells 
were harvested for RNA extraction using a Qiagen RNA kit. Three samples of each group (on top of plastic or Myogel coating) were pooled; the pools contained an equal amount of RNA from each sample. Affymetrix GeneChip Human Genome U133 Plus 2.0 Arrays were used for microarray analysis and experimental procedures were performed according to the Affymetrix GeneChip Expression Analysis Technical Manual. Briefly, $1 \mu \mathrm{g}$ of total RNA was used as a template to synthesize biotinylated cRNA by means of the GeneChip 3'IVT Express kit (Affymetrix) according to the manufacturer's instructions. The cRNA was fragmented to 35 to $200 \mathrm{nt}$ prior to hybridization to Affymetrix Human Genome U133 Plus 2.0 arrays containing approximately 55,000 human transcripts. The array was washed and stained with streptavidin-phycoerythrin (Molecular Probes). Finally, biotinylated anti-streptavidin (Vector Laboratories Inc.) was used to amplify the staining signal and a second staining was performed with streptavidin-phycoerythrin. The arrays were scanned on a GeneChip Scanner 3000 (Affymetrix, High Wycombe, United Kingdom). The expression data was analyzed to find genes with fold changes (FC) of 1.5 or more using dChip software [31]. The genes with FC 1.2 or more were divided into Gene Ontology (GO) categories using a dChip enrichment analysis tool.

\section{Scratch assay}

To analyze the effects of Myogel and Matrigel $^{\circ}$ (BD Matrigel Matrix, BD Biosciences, Cat. Number 354234) on the migration of HSC-3 cells, 24-well plates were coated with $0.62 \mathrm{mg} / \mathrm{ml}$ Myogel (two different batches) or $0.62 \mathrm{mg} / \mathrm{ml} \mathrm{Matrigel}^{\circ}$. The coating was left to solidify for $2 \mathrm{~h}$ at $37^{\circ} \mathrm{C}$ and then washed twice with PBS. HSC-3 cells $(90,000)$ were allowed to attach overnight, and were then wounded with a pipette tip, rinsed twice with PBS, post-coated for $1 \mathrm{~h}$ and rinsed before $1 \%$ FBS medium was added. The wounds were photographed with an EVOS photomicroscope at $0 \mathrm{~h}$ and $24 \mathrm{~h}$ after scratching. The area of the open wound was measured using ImageJ software and the results were calculated as a percentage of wound closure.

\section{Transwell invasion through Myogel and Matrigel ${ }^{\circledR}$}

To compare Myogel with Matrigel ${ }^{\circ}$ (BD Matrigel Matrix, BD Biosciences, Cat. Number 354234) as an invasion assay material, experiments were carried out according to BD Biosciences instructions to coat the filter membranes with Matrigel ${ }^{\circ}$. Fifty $\mu \mathrm{l}$ of either $1+1$ Matrigel $^{\circ}$ or Myogel (three different batches at the same protein concentration as Matrigel $^{\circ}$ ) diluted with serum-free medium was added to the upper chamber of a Transwell ${ }^{\circ}$ nylon filter membrane insert (Corning Inc.), incubated at $37{ }^{\circ} \mathrm{C}$ in a $5 \% \mathrm{CO}_{2}$ humidified atmosphere for $30 \mathrm{~min}$ after which 50,000 HSC-3 cells suspended in $100 \mu \mathrm{l}$ of serum- free medium were seeded onto the upper compartment of the Transwell ${ }^{\circ}$ chambers. The Transwell ${ }^{\circ}$ inserts were incubated for $12 \mathrm{~h}-48 \mathrm{~h}$ at $37{ }^{\circ} \mathrm{C}$ in a $5 \% \mathrm{CO}_{2}$ humidified atmosphere, after which the cells were fixed in $10 \%$ TCA for $15 \mathrm{~min}$, rinsed and air-dried overnight. Once dry the membranes were stained with crystal violet for 20 min and the excess stain was removed by water rinsing. The non-invasive cells from the upper side of the membrane were removed by carefully sweeping with a cotton swab. Next, the membranes were removed from the inserts and placed on microscope slides and the number of invaded cells through Myogel and Matrigel ${ }^{\circ}$ were counted. We also tested different mixtures of Myogel and Matrigel $^{\circ}(2+1,1+1$ and $1+2)$ in the invasion assay.

\section{Transwell invasion with Myogel solidified with low-melting agarose (Myogel-LMA)}

We used a final concentration of $0.2 \%$ LMA in $3.2 \mathrm{mg} /$ $\mathrm{ml}$ final Myogel protein concentration to solidify Myogel for invasion assays. To compare the results with Matrigel $^{\circ}$ we diluted Matrigel $^{\circ}$ (BD Matrigel Matrix, BD Biosciences, Cat. Number 354234) $1+4$ (final protein concentration $2.0 \mathrm{mg} / \mathrm{ml}$ ) with the same concentration of $0.2 \%$ agarose. Serum-free cell culture medium was used for gel dilution. Fifty $\mu \mathrm{l}$ of the Myogel-LMA or Matrigel agarose mixtures was added on the upper chamber of Transwell ${ }^{\circ}$ nylon filter membrane insert, incubated $1 / 2 \mathrm{~h}$ at $\mathrm{RT}$ and thereafter at $37^{\circ} \mathrm{C}$ in a $5 \% \mathrm{CO}_{2}$ humidified atmosphere until the cells were ready to be seeded on the top of the gel. HSC-3 cells were trypsinized and counted, trypsin inhibitor instead of serumcontaining medium was used to inactivate trypsin. Five hundred $\mu \mathrm{l}$ of $10 \%$ serum containing medium was added into the lower chamber of the Transwell ${ }^{\circ}$, and 50,000 HSC-3 cells suspended into $100 \mu \mathrm{l}$ of medium containing $0.5 \%$ lactalbumin instead of serum were seeded into the upper compartment of the Transwell ${ }^{\circ}$ chamber. The cells were allowed to invade for one to three days and the invasion was quantified by staining the cells with crystal violet followed by counting the cell number. In this preliminary assay we tested different agaroses and concentrations with only one $\mathrm{Transwell}^{\circ}$ in each condition and $0.2 \%$ LMA was chosen for further experiments. In another set of experiments, the invasion of SCC-9, LN-1, LN-2, HSC-3, SK-Mel-25 and A2058 cells was studied in Myogel-LMA and growth factorreduced Matrigel $^{\circ}$ (Matrigel ${ }^{\circ}$-GFR, BD Matrigel Matrix, BD Biosciences, Cat. Number 35430) diluted $1+1$ with serum free medium without LMA. The invasion was quantified with Toluidine Blue -staining. Briefly, after $72 \mathrm{~h}$ invasion, the cells were fixed with $4 \%$ formaldehyde for $1 \mathrm{~h}$ at RT, washed once with PBS, stained for 5-10 $\mathrm{min}$ in Toluidine blue solution (filtered $1 \%$ 
Toluidine Blue $+1 \%$ disodium tetraborate in $\mathrm{ddH}_{2} 0$ ) at $\mathrm{RT}$, excess dye was rinsed out with deionized water, excess gel and the cells from the upper side of the membrane were removed by using cotton swabs and when necessary, excess dye was further removed from the inside and outside of the Transwell ${ }^{\circ}$ inserts with cotton swabs immersed in a solution of 1:1 water/ethanol. The dye was eluted by dipping the Transwell ${ }^{\circ}$ inserts in a solution of $1 \%$ SDS $(500 \mu \mathrm{l})$. The $1 \%$ SDS solution containing the eluted dye was transferred into a 96-well plate and the absorbance was measured at $650 \mathrm{~nm}$.

\section{Hanging drop method}

The gel from rat tail type I collagen (BD Biosciences) was prepared according to the manufacturer's protocol, with a final collagen concentration of $1.7 \mathrm{mg} / \mathrm{ml}$. The collagen/Matrigel ${ }^{\circ}$ (BD Matrigel Matrix, BD Biosciences, Cat. Number 354234$)(1.5 \mathrm{mg} / \mathrm{ml}, 1.5 \mathrm{mg} / \mathrm{ml})$ and collagen/Myogel $(1.5 \mathrm{mg} / \mathrm{ml}, 4.3 \mathrm{mg} / \mathrm{ml})$ mixtures were prepared similarly. The hanging drop technique was used to observe the cell movement under 3D culture conditions. HSC-3 (H2B-GFP) cells were washed with PBS, trypsinized and 70,000 cells in $10 \mu \mathrm{l}$ of DMEM/F12 medium ( $2 \% \mathrm{FBS}$ ) were mixed with $50 \mu \mathrm{l}$ of the matrix mixture. Twenty $\mu \mathrm{l}$ of the cell suspension in each matrix was dropped on the 4 compartment plate. The plate was inverted after $5 \mathrm{~min}$ incubation in culturing conditions and incubated for $3 \mathrm{~h}$ in a humidified chamber in culturing conditions. Mimosine $(200 \mu \mathrm{M})$ was added to the medium to synchronize the cell cycle. Images were taken with a Zeiss Axio Observer.Z1 with a EC Plan-Neofluar 40x/0.75 M27 objective (Göttingen, Germany). Images consisting of $1024 \times 1024$ pixels were taken every 15 min with a $19.8 \mu \mathrm{m}$ Z-stack volume $(0.6 \mu \mathrm{m}$ thickness) with a Hamamatsu Camera\# 2 controlled by Zeiss Zen Blue software (Zeiss) for $20 \mathrm{~h}$. This assay was performed twice. The analysis of the cells in hanging drops is described in the Additional file 2: Supplementary Method.

\section{In vitro capillary tube formation assay}

96-well culture plates were coated with Myogel with $2 \%$ low melting agarose (Myogel-LMA), Matrigel ${ }^{\circ}$-GFR (BD Matrigel Matrix, BD Biosciences, Cat. Number 35430) or ECMatrix ${ }^{\text {tix }}$ (ECMatrix - In vitro Angiogenesis Assay Kit, Cat. Number ECM625 - Millipore) previously thawed overnight on ice, in a total volume of $50 \mu \mathrm{l} /$ well and allowed to solidify overnight at $37^{\circ} \mathrm{C}$. HUVEC cells were trypsinized, neutralized with DMEM/F12 with $10 \%$ FBS, washed once with PBS and resuspended in DMEM/F12 at a density of $450,000 / \mathrm{ml}$. Hundred $\mu \mathrm{l}$ of this cell suspension was added into each well and the plates were incubated at $37^{\circ} \mathrm{C}$ for $12 \mathrm{~h}$. Tube formation was observed under an inverted microscope $(4 \mathrm{x}$, Eclipse
Ti-S, Nikon, Tokyo, Japan) and photos were taken and analyzed using the Motic Images Plus 2.0 software (Motic). Tubule perimeters were assessed by drawing a line around each tubule and measuring the length of the line.

\section{Statistical analysis}

SPSS for Windows software version 21.0 (IBM) or GraphPad Prism 6 (GraphPad Software) were used for statistical analyses. To establish the statistical significance of differences between the two independent cell culture groups, a Mann-Whitney $U$ test was used to compare the groups.

\section{Results}

The protein composition in different Myogel batches is reproducible and differs from that of Matrigel $^{\oplus}$

The reproducibility of different Myogel batches was first investigated in Coomassie Blue stained gradient SDSPAGE gels. Different Myogel preparations and the mixture of various batches showed relatively similar protein band patterns, and only slight variations in the intensities of differently sized bands were visible (Additional file 1: Figures S1A and S1B). Two Myogel batches were further investigated by 2-DE (Additional file 1: Figure $\mathrm{S} 1 \mathrm{C})$ which confirmed with almost similar protein patterns in the silver stained 2D gels likewise the high reproducibility of these Myogel preparations.

After that the protein compositions of Myogel and Matrigel ${ }^{\triangleright}$ were compared. In SDS-PAGE gels more bands were detected for the Myogel (Additional file 1: Figure $\mathrm{S} 1 \mathrm{~A}$ ) and also the 2-DE separation showed a significant difference between Matrigel $^{\circ}$ and Myogel samples (Additional file 1: Figure S1C). If similar protein amounts $(100 \mu \mathrm{g})$ were separated significantly more spots were visible for the Myogel. Increasing the amount of Matrigel $^{\circ}$ proteins to $300 \mu \mathrm{g}$ resulted in a significantly higher number of detectable spots (Additional file 1: Figure S1C). This suggests that a few high abundant proteins, including these visible in the gel with lower protein amount, comprise a major part of the $\mathrm{Matrigel}^{\circ}$ proteome. However, also with higher protein amounts Matrigel $^{\circ}$ and Myogel showed still distinct protein patterns. The here shown differences between Myogel and Matrigel ${ }^{\bullet}$ proteomes are possibly due to the difference between species (human vs. mouse) and the nature of the starting material (leiomyoma vs. sarcoma).

We next analyzed the protein content of Myogel and compared it with the published data of $\mathrm{Matrigel}^{\circ}$ [3234]. For further proteomic analyses, different Myogel batches were separated by gradient SDS-PAGE (Additional file 1: Figure S1B). Since Myogel batch number 4 differed most from the other three batches (3, 6 and 9; Additional file 1: Figure S1B), it was omitted from the 
mass spectrometry analysis. Two of the Myogel samples gave successful results, and altogether 765 proteins were identified (Additional file 3: Table S1). Among the Myogel proteins, $34 \%$ (259 proteins) were the same as in Matrigel $^{\circ}$ where 1030 proteins were identified. Based on the comparison, for instance laminin, type IV collagen, heparan sulfate proteoglycans, nidogen and epidermal growth factor were found in both. Based on mass spectrometry analysis, Myogel lacked enactin, which is present in Matrigel ${ }^{\circ}$, but contained for example tenascin-C, collagen types XII and XIV, etc., which were lacking in Matrigel $^{\circ}$. Based on zymography, Myogel contained both latent and active forms of MMP-2, whereas in Matrigel latent and active forms of both MMP-2 and MMP-9 were present (Additional file 1: Figure S1D) as shown earlier [35].

\section{The $\mathrm{pH}$ of Myogel is neutral and more stable than the $\mathrm{pH}$ of Matrigel ${ }^{\oplus}$}

The $\mathrm{pH}$ of Myogel was initially between 7.0 and 7.5, and after $48 \mathrm{~h}$ incubation the $\mathrm{pH}$ remained the same. The $\mathrm{pH}$ of Myogel with HSC-3 cells on top dropped slightly from 7.0-7.5 to 6.5-7.0 ( $0 \mathrm{~h}$ and $48 \mathrm{~h}$ incubations, respectively), whereas in Matrigel $^{\circ}$ the $\mathrm{pH}$ at the same time dropped from a slightly alkali $8.0-8.5$ to as low as 6.0-6.5 (Additional file 4: Table S2). This indicates that Myogel samples are closer than Matrigel $^{\circ}$ to neutral $\mathrm{pH}$, and Myogel keeps the $\mathrm{pH}$ more stable than Matrigel $^{\circ}$ during cancer cells culture experiments.

\section{Fibroblasts adhere to Myogel, but only HSC-3 cells form colonies within Myogel- soft agar assay}

HSC-3 cells adhered significantly more to plates precoated with Myogel than with BSA, or to the plain plates kept in PBS. However, they adhered even more readily to Matrigel ${ }^{\circ}$ coated plates (Fig. 1). The adhesion experiment with gingival fibroblasts (GFs) showed that after $9.5 \mathrm{~h}$ incubation on top of Myogel, fibroblasts were well spread and vital (not shown). Based on the TUNEL assay, from 98 to $99 \%$ of the carcinoma associated fibroblasts (CAFs) seeded on top of various batches of Myogel were alive even after $24 \mathrm{~h}$ incubation (not shown). However, when CAFs were embedded within the Myogel matrix, almost all died within 21 days (not shown). In contrast, embedded HSC-3 cells stayed alive up to 28 days, divided and formed colonies within Myogel combined with LMA. The results with HSC-3 cells were relatively similar using either Myogel-LMA or a conventional soft agarose (LMA) assay (Figs. 2a and b); in Myogel-LMA the colony number was six percent less than in LMA (47 vs. 50). However, more colonies with the lowest cell number were present in LMA, while the highest cell number/colony was present in Myogel-LMA (Fig. 2b). According to nuclear RFP expression, $92 \%$ of the cancer cells were alive in Myogel-LMA colonies,

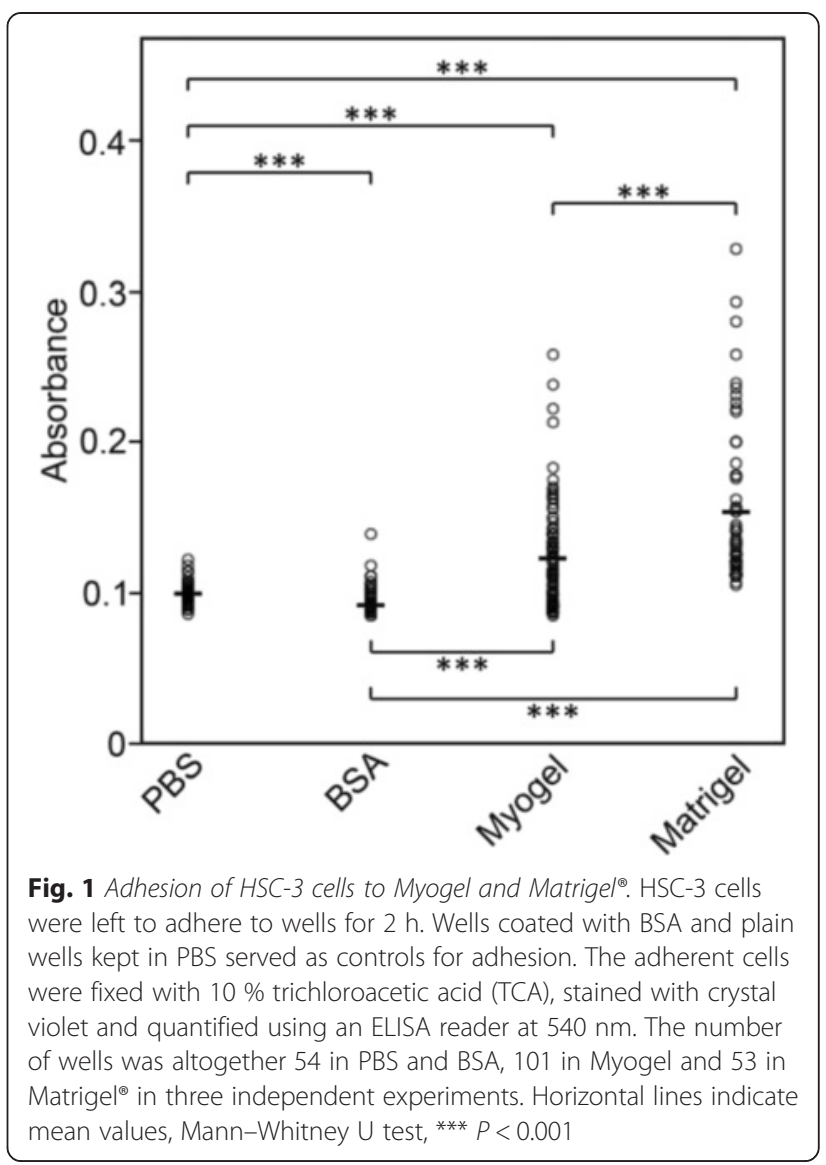

whereas $85 \%$ were alive in LMA colonies. The total average area of cell colonies in Myogel-LMA was three percent less than in LMA (not shown). In HSC-3 cell hanging drop spheroid cultures the area of the spheroids embedded in Myogel-LMA grew more in $24 \mathrm{~h}$ incubation than in spheroids embedded in plain LMA (Fig. 2c and $\mathrm{d}$ ). The area growing rate remained higher in Myogel-LMA even during $72 \mathrm{~h}$ follow-up and the spheroid area enlarged more in ratio to $0 \mathrm{~h}$ area in MyogelLMA cultures than in plain LMA cultures (Fig. 2c and d). On average the increase at $72 \mathrm{~h}$ in ratio to $0 \mathrm{~h}$ was $21.5 \%$ in Myogel-LMA and $12.2 \%$ in plain LMA. In the most enlarged spheroids, the area increase at $72 \mathrm{~h}$ in Myoogel-LMA was $63.5 \%$ while in plain LMA it was only $43.1 \%$ (Fig. 2d). In less enlarged spheroids, the average increase at $72 \mathrm{~h}$ in Myogel-LMA was $11.0 \%$ whereas in plain LMA it was $4.5 \%$ compared to $0 \mathrm{~h}$ spheroids (Fig. 2d).

Gene expression is changed when HSC-3 cells are cultured on top of Myogel compared to the same cells cultured on plastic

Gene expression assays are usually done with cells grown on tissue culture plastic. We wanted to see if Myogel coating has an effect on expressed genes in 

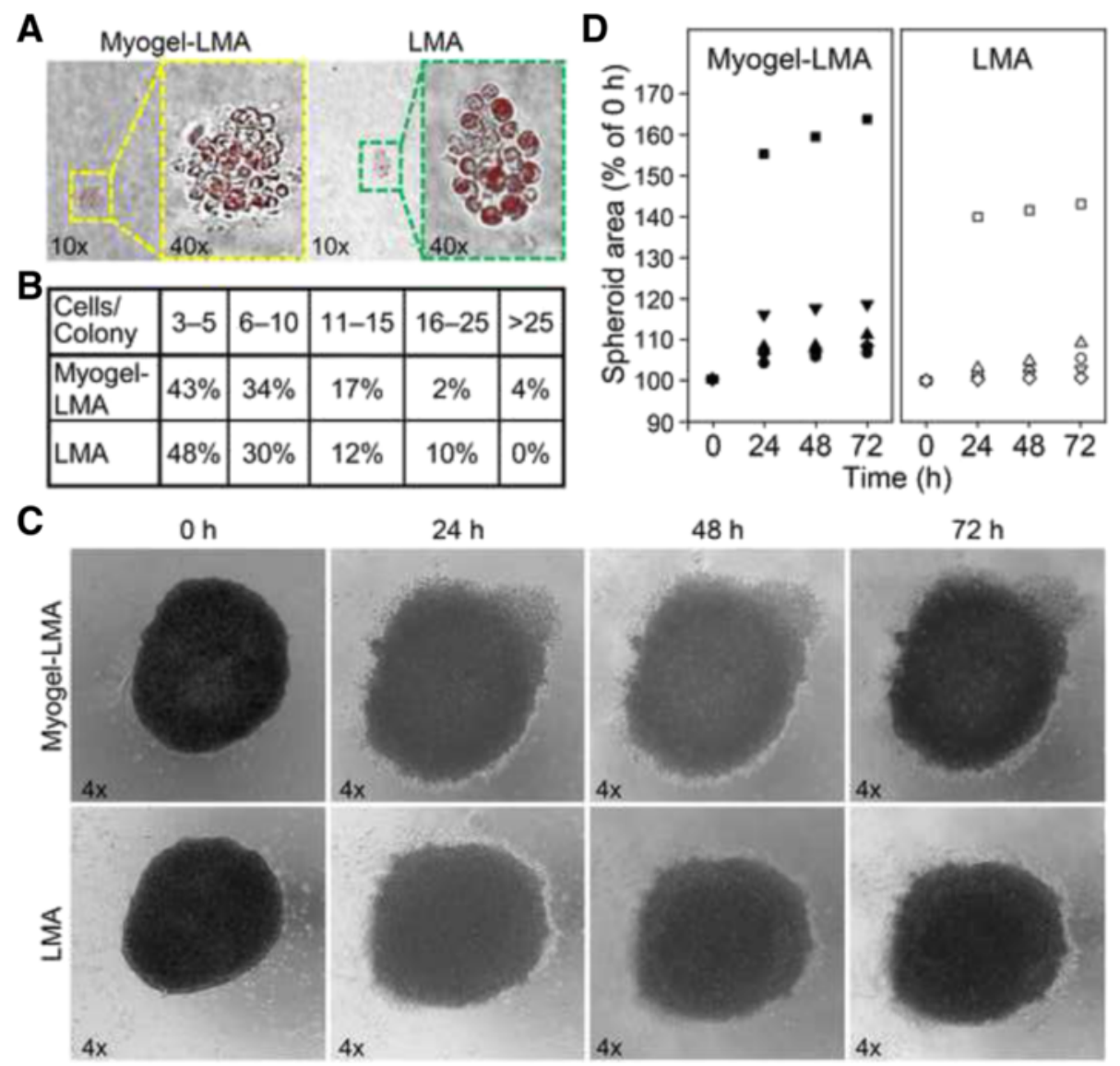

Fig. 2 Colony formation and hanging drop spheroid culture of HSC-3 cells within Myogel combined with LMA and plain LMA. Colonies were photographed with 10x and 40x objectives (a). Cell numbers per colony were counted from the photographs (b). Spheroids were photographed with $4 \times$ objective (c). Spheroid area in ratio to $0 \mathrm{~h}$ spheroid area was calculated after $24 \mathrm{~h}, 48 \mathrm{~h}$ and $72 \mathrm{~h}$ incubations (d). Altogether 47 colonies were calculated from four Myogel-LMA and 50 colonies from four LMA wells in two independent experiments. Enlargement of altogether five spheroids in both Myogel-LMA and LMA was followed in two independent experiments

HSC-3 cells compared to cells grown on plain plastic. Approximately $1.4 \%$ of the genes (totally 751 ) were differentially expressed (FC 1.5 or more) when the HSC-3 cells cultured on the top of plastic were compared to the corresponding cells grown on Myogel (raw data presented in Additional file 5: Table S3 showing 807 probes). When the genes were divided into groups according to their biological function we found that the Myogel coating affected those genes that are related to intracellular organelle and cytoskeleton organization and biogenesis. A significant change in pathway analysis was found only in the G13 signaling pathway that is related to actin polymerization and reorganization (www.genmapp.org).

\section{The vertical migration of HSC-3 cells is faster on Myogel} than on Matrigel ${ }^{\oplus}$ coated wells

In the scratch assay, HSC-3 cells migrated significantly more in Myogel coated wells than in wells coated with
Matrigel $^{\circ}$ (Fig. 3a and b). However, in uncoated wells their migration was faster than in coated wells (Fig. 3a and b).

\section{HSC-3 cells invade more efficiently through Myogel than Matrigel $^{\oplus}$}

In order to test the use of Myogel on cancer invasion Transwell $^{\circ}$-assays, we first compared the invasion of the most aggressive oral tongue carcinoma cell line (HCS-3) using Myogel and Matrigel ${ }^{\circ}$. The HSC-3 cells invaded significantly more efficiently through Myogel than Matrigel $^{\circ}$ (Fig. 4a). Invasion varied slightly in different Myogel batches, but HSC-3 cells invaded in all Myogel samples more than in Matrigel ${ }^{\circ}$ (Fig. 4b). When Myogel and Matrigel $^{\circ}$ were mixed, HSC-3 cells invaded more efficiently when the mixture contained more Myogel, and less when the portion of Matrigel ${ }^{\circ}$ increased (Fig. 4c). The invasion pattern of HSC-3 cells was different in Myogel and Matrigel ${ }^{\circ}$. The cells invaded more evenly throughout the whole Transwell $^{\circ}$ membrane in Myogel 
A

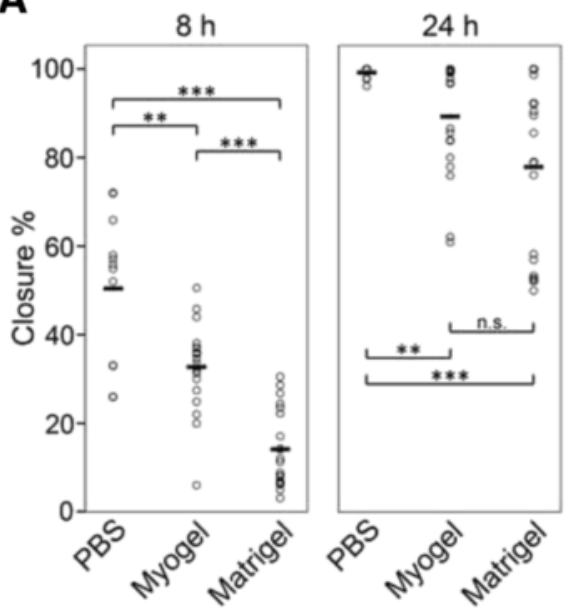

B

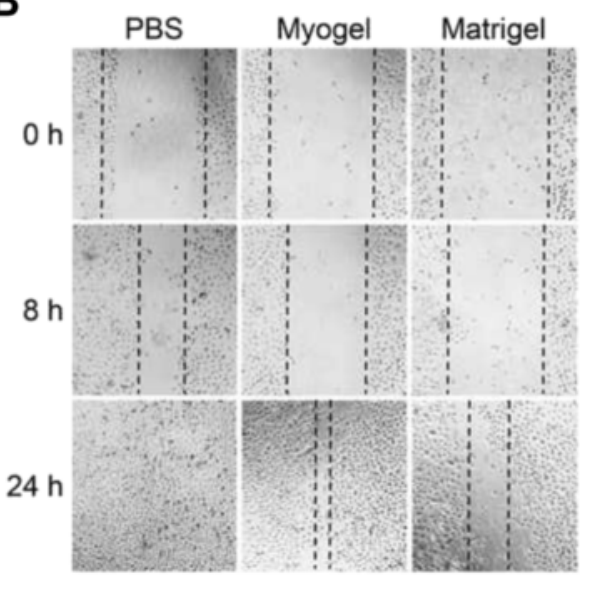

Fig. 3 Migration of HSC-3 cells on Myogel and Matrigel ${ }^{\oplus}$. HSC-3 cells migrated for $24 \mathrm{~h}$ in the scratch assay on Myogel and Matrige ${ }^{\circledR}$ coated wells (a). Dash line in (b) represents the edges of the wounds. Altogether twelve wounds without coating (PBS) and twenty with Myogel or Matrigel ${ }^{\circledR}$ coating were measured in two independent experiments. Horizontal lines indicate mean values, Mann-Whitney $U$ test, n.s. not significant,

** $P<0.01$, *** $P<0.001$
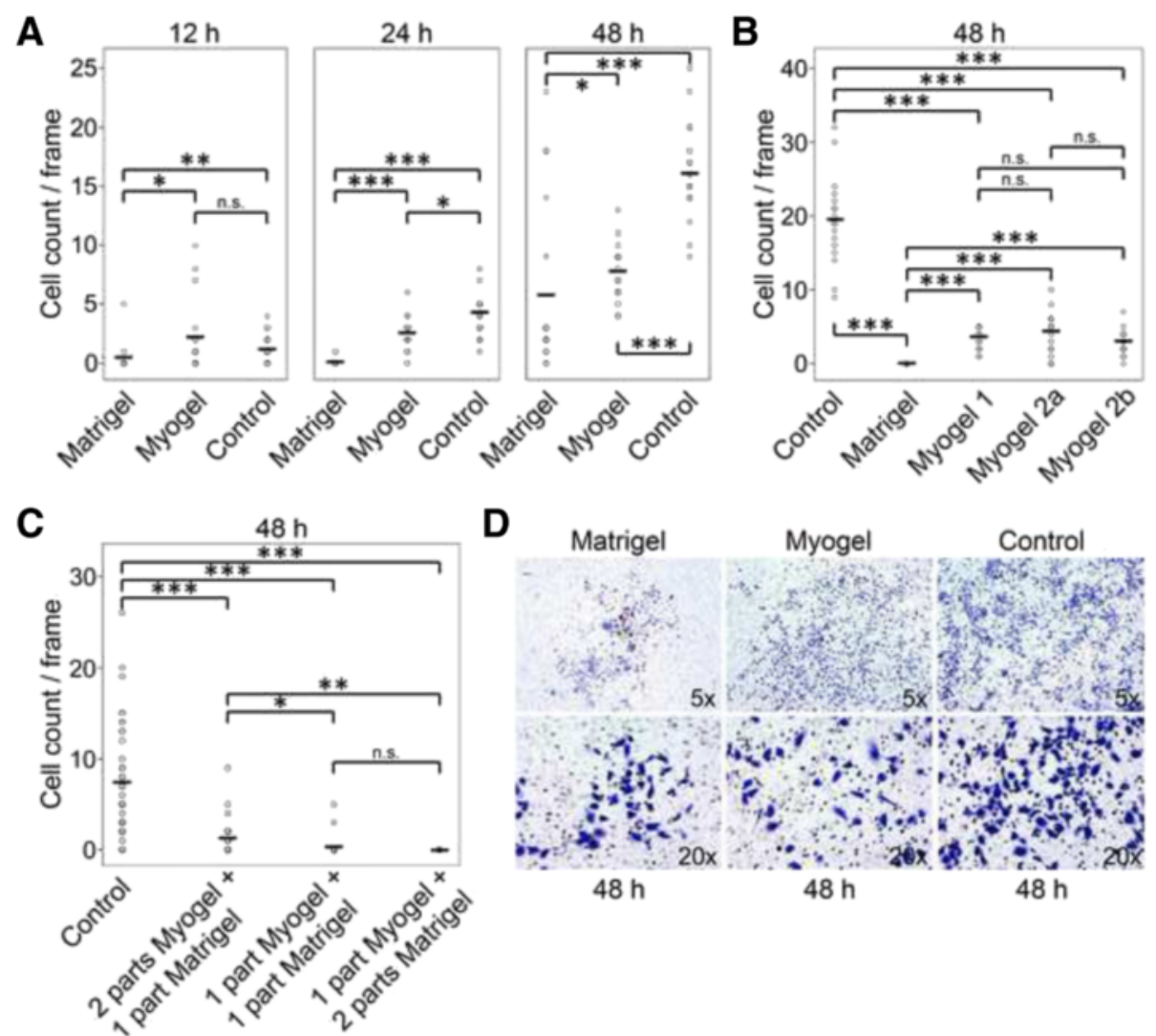

Fig. 4 Invasion of HSC-3 cells through Myogel and Matrigel ${ }^{\oplus}$. HSC-3 cells were allowed to invade for $12-48 \mathrm{~h}$ through Myogel and Matrigel ${ }^{\circledR}$ (a). Three different Myogel batches were compared to Matrigel ${ }^{\circledR}$ in HSC-3 cells invasion (b). Invasion of HSC-3 cells in different mixtures of Myogel and Matrige $\left.\right|^{\oplus}$ (c). Invasion pattern of HSC-3 cells through Myogel and Matrige ${ }^{\oplus}(\mathbf{d})$. In $\mathbf{a}$ and $\mathbf{b}$ the number of Transwell ${ }^{\otimes} \mathrm{S}$ was three in every group, in c Transwell ${ }^{\oplus}$ number was six in the control group and three in the other groups, cells from six areas of each Transwell ${ }^{\circledR}$ were calculated. Each invasion assay ( $\mathbf{a}, \mathbf{b}$ and $\mathbf{c}$ ) was performed as an independent experiment. Controls were Transwell ${ }^{\oplus} \mathrm{s}$ without coating. Horizontal lines indicate mean values, Mann-Whitney $U$ test, n.s. not significant, ${ }^{*} P<0.05,{ }^{*} P<0.01$, ${ }^{* * *} P<0.001$ 
coated filters, whereas in Matrigel $^{\bullet}$ experiments they invaded more in clumps (Fig. $4 \mathrm{~d}$ ).

\section{Myogel solidified with agarose (Myogel-LMA) is a more feasible matrix for invasion assays}

Since Myogel batches vary slightly in their protein content, as seen in the gradient gel in Additional file 1: Figures S1A and $\mathrm{S} 1 \mathrm{~B}$, we created a more homogenous, reliable and easier to handle matrix by adding low-melting agarose into the Myogel mixture. We noticed that HSC-3 cells did not invade through a plain agarose coated membrane, but they invaded through a Myogel-agarose (Myogel-LMA) mixture (Fig. $5 \mathrm{a}$ and b). Interestingly, the passage number of the HSC-3 cells seemed to affect the invasion through Myogel- and Matrigel ${ }^{\circ}$-mixtures; cells with higher passages invaded slightly less through Matrige $^{\circ}$ mixtures than through Myogel-containing mixtures, whereas cells with a low passage number invaded slightly less through MyogelLMA than through Matrigel ${ }^{\circ}$-LMA (Fig. 5a). The invasion pattern of HSC-3 cells through agarose-containing mixtures was similar to that observed in plain Myogel or Matrigel $^{\oplus}$; in Myogel-LMA mixtures cells invaded more

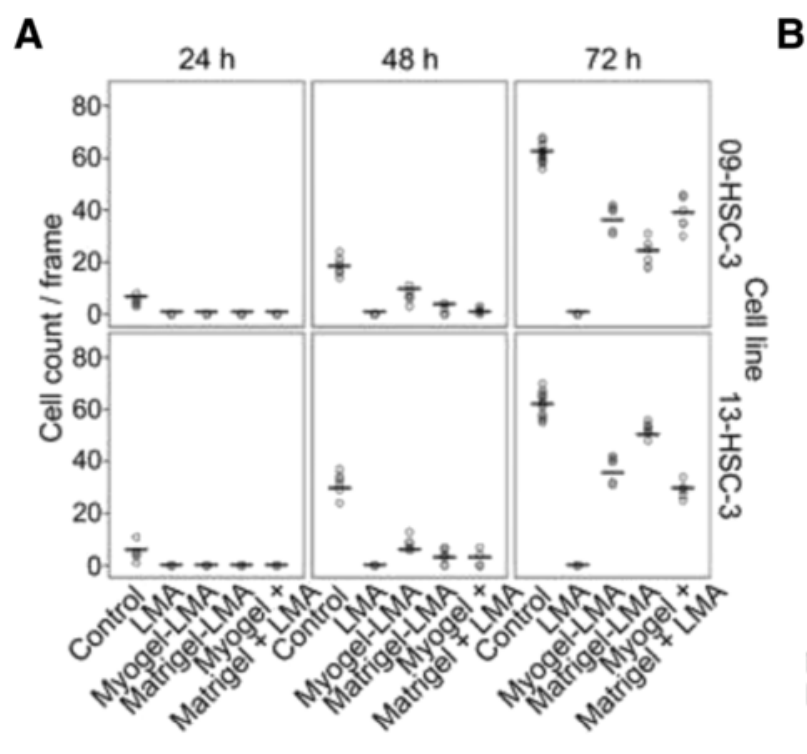

B
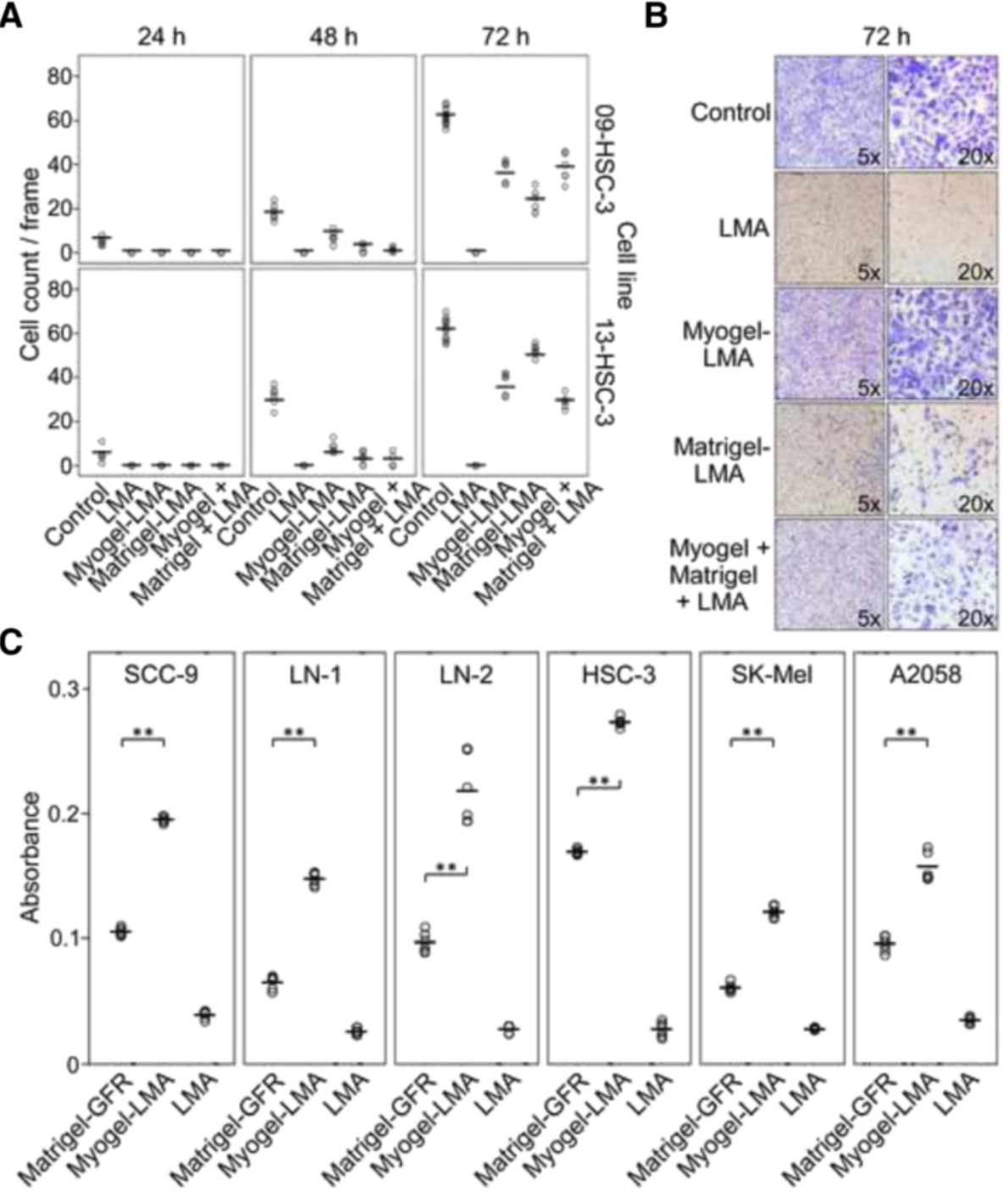

Fig. 5 Invasion of oral squamous cell carcinoma and melanoma cells through Myogel-LMA and Matrige ${ }^{\circledR}$ or Matrigel ${ }^{\circledR}$-GFR. HSC-3 cells were allowed to invade for three days through Myogel and Matrige ${ }^{\circledR}$ mixed with agarose, 09-HSC-3 cells have a higher passage number than $13-\mathrm{HSC}-3$ cells (a). Invasion pattern of HSC-3 cells through different mixtures of Myogel, Matrigel ${ }^{\circledR}$ and LMA (b). Oral squamous cell carcinoma and melanoma cells were allowed to invade for $72 \mathrm{~h}$ through Myogel-LMA and through Matrigel ${ }^{\circledR}$-GFR (c). In a one Transwell ${ }^{\circledR}$ was analyzed for each group except for control at $72 \mathrm{~h}$ there were two filters (controls were Transwell ${ }^{\oplus} \mathrm{s}$ without coating), six areas per filter were calculated, in $\mathbf{c}$ altogether six Transwell ${ }^{\oplus} \mathrm{S}$ were analyzed in each group in two independent experiments. As only one filter was analyzed in preliminary experiment with LMA in a, statistical significances were not calculated in that experiment. In c differences were not statistically compared to plain LMA. Horizontal lines indicate mean values, Mann-Whitney $U$ test, ${ }^{* *} P<0.01$ 
evenly throughout the whole Transwell ${ }^{\circ}$ membrane than in Matrigel ${ }^{\circ}$-LMA mixtures (Fig. 5b).

In another experiment, Myogel-LMA was compared with Matrigel $^{\circ}$-GFR. In general, all the oral squamous cell carcinoma cell lines used for these invasion assays (HSC-3, LN-1, LN-2 and SCC-9) preferred MyogelLMA to Matrigel $^{\circ}$-GFR during the invasion (Fig. 5c). HSC-3 and LN-2 (in this order) seemed to have a higher potential to invade in both Myogel-LMA and Matrigel ${ }^{\circ}$ GFR, compared to the LN-1 and SSC-9 cell lines. The cells invading the Myogel-LMA seemed to keep more of the morphological characteristics observed in monolayer cultures. In contrast, the cells grouped together as they invaded the Matrigel ${ }^{\circ}$-GFR matrix, and lost the "fusiformstarshape" characteristic of oral carcinoma cell lines (not shown). In addition to oral carcinoma cell lines, we tested Myogel-LMA on SK-Mel and A2058 melanoma cell lines and found that also they invaded Myogel-LMA more efficiently than Matrigel ${ }^{\circ}$-GFR (Fig. 5c).

\section{HSC-3 cells move faster in Myogel-collagen matrix than in Matrigel ${ }^{\oplus}$-collagen matrix in the 3D hanging-drop cultures}

To observe the cell behavior in 3D culture in different matrices, we have established an optimized hanging drop method modified from the previously reported protocol [36]. HSC-3 cells moved in a relatively similar fashion in pure collagen, Myogel-collagen and Matrigel ${ }^{\circ}$-collagen matrices (Additional file 6: Movie S1, Additional file 7: Movie S2 and Additional file 8: Movie S3). However, interestingly the speed of the cells was highest in the Myogelcollagen matrix and lowest in the Matrigel ${ }^{\circ}$-collagen matrix (Additional file 1: Figure S2, Additional file 6: Movie S1, Additional file 7: Movie S2 and Additional file 8: Movie S3).

Myogel efficiently induces endothelial cell tube formation In vitro angiogenesis assays are commonly used to assess pro- or anti-angiogenic drug properties [37]. Here, tube formation could be quantified in all matrix-assays tested (Fig. 6a). With Myogel-LMA, tube formation was visible after $12 \mathrm{~h}$, and even after $72 \mathrm{~h}$ the endothelial cells were alive (Fig. 6a), unlike in Matrigel $^{\oplus}$-GFR or ECMatrix ${ }^{\mathrm{TM}}$ (not shown), where most of the HUVEC cells were already apoptotic after $24 \mathrm{~h}$. We found that the number of tubules formed was three times higher in MyogelLMA compared to ECMatrix ${ }^{\mathrm{Tm}}$ (Fig. 6b). Otherwise, measuring the diameters of the capillaries, the tubule parameters in Matrigel $^{\circ}$-GFR, and especially in ECMatrix ${ }^{\mathrm{TM}}$ assays, were significantly higher than in tubes formed in Myogel-LMA (Fig. 6c).

\section{Discussion}

There has been a lack of a gelatinous soluble human tumor microenvironment matrix (TMEM) for human cell line experiments in vitro. Today, the most widely used TMEM gelatinous material is mouse sarcomaderived $\mathrm{Matrigel}^{\circledR}$ and other commercial and modified derivatives of mouse EHS tumors. Here, we described the preparation and use of a novel TMEM matrix, Myogel, which is derived from human uterus leiomyoma tissue. We have previously reported the use of leiomyoma tumor solid discs in several invasion studies [1-8]. Now we demonstrate that both Myogel and its combination with low melting agarose, Myogel-LMA, provide practical in vitro gelatinous TMEM for testing cancer cells invasive, adhesive or migratory properties, that is similar to Matrigel $^{\circledR}$, Matrigel ${ }^{\circ}$-GFR or ECMatrix ${ }^{\mathrm{Tm}}$. The benefit of Myogel over various EHS tumor derived products is that the protein composition of human Myogel differs significantly from the mouse sarcoma matrix as seen by gradient SDS-PAGE gels, 2-DE, zymography and proteomics analyses. Moreover, the $\mathrm{pH}$ is more stable in Myogel than in Matrigel $^{\odot}$ during cell culture. In addition, human uterus myomas, which are by-products of surgical operations, are an ethically superior starting material compared to EHS tumors in mice, which are grown purely for preparing TMEM for research purposes. Myogel and in particular Myogel-LMA, is easy to prepare and handle. Finally, and most importantly, in all assays we have tested thus far, the results have been reproducible and similar or even superior to Matrigel $^{\oplus}$. Namely, the various cancer cells analyzed invaded through Myogel or Myogel-LMA generally more efficiently than through Matrigel $^{\circledR}$ or Matrigel $^{\circledR}$-GFR. Embedded HSC-3 cells tended to form larger colonies and spheroids in soft agar colony formation -assay and in hanging drop spheroid cultures, respectively, within Myogel-LMA than within plain LMA. HUVEC cells in Myogel-LMA formed more and smaller tubules which lasted longer than in Matrigel-GFR ${ }^{\odot}$ or in ECMatrix. In addition, we demonstrated in hanging drop assays that carcinoma cells were able to move more rapidly in a Myogel-collagen matrix than in collagen, or in Matrigel $^{\circledR}$-collagen combinations.

Uterine leiomyomas are benign smooth muscle tumors affecting the health of millions of females. The tumors have at least four molecular subclasses and contain chromothripsis, which has previously been associated with aggressive cancer $[38,39]$. As a patient derived material, there is heterogeneity between myomas. The operating surgeon omits peculiar ones. The prepared batch is always tested in an invasion assay with our reference HSC-3 cells. To ensure the reproducibility between the Myogel batches, we combine several myomas for each batch. As a solid tumor mass, easy to obtain and handle, myoma tissue is an ideal matrix material for several experimental cancer study applications in vitro. At present, all the other human ECM matrices to investigate the properties of cancer cell lines are derived either from 


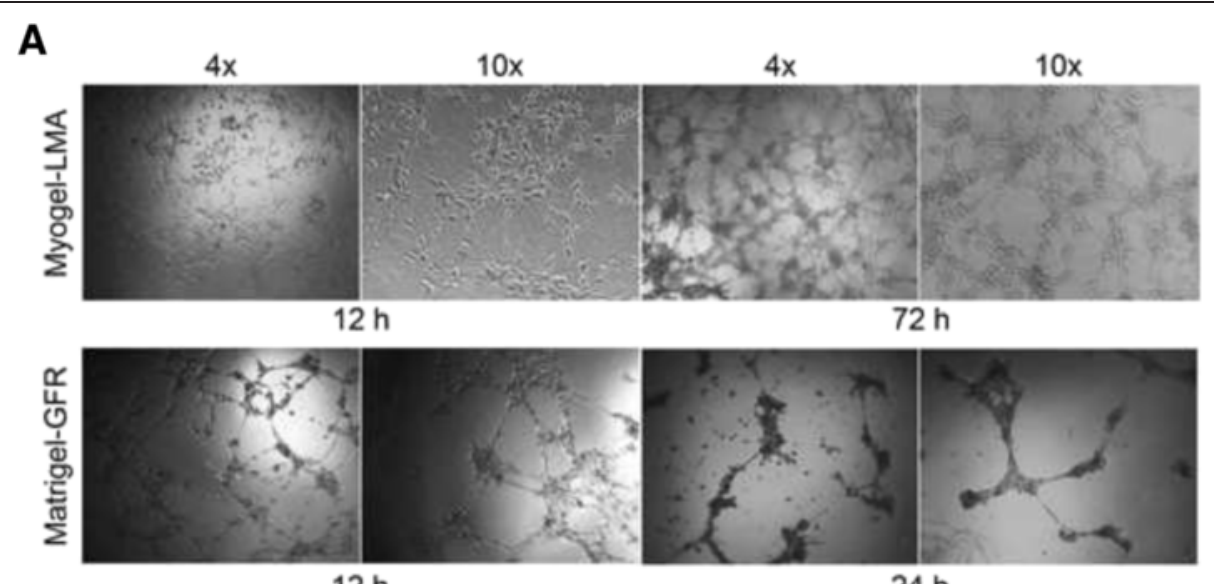

$12 \mathrm{~h}$

$24 \mathrm{~h}$
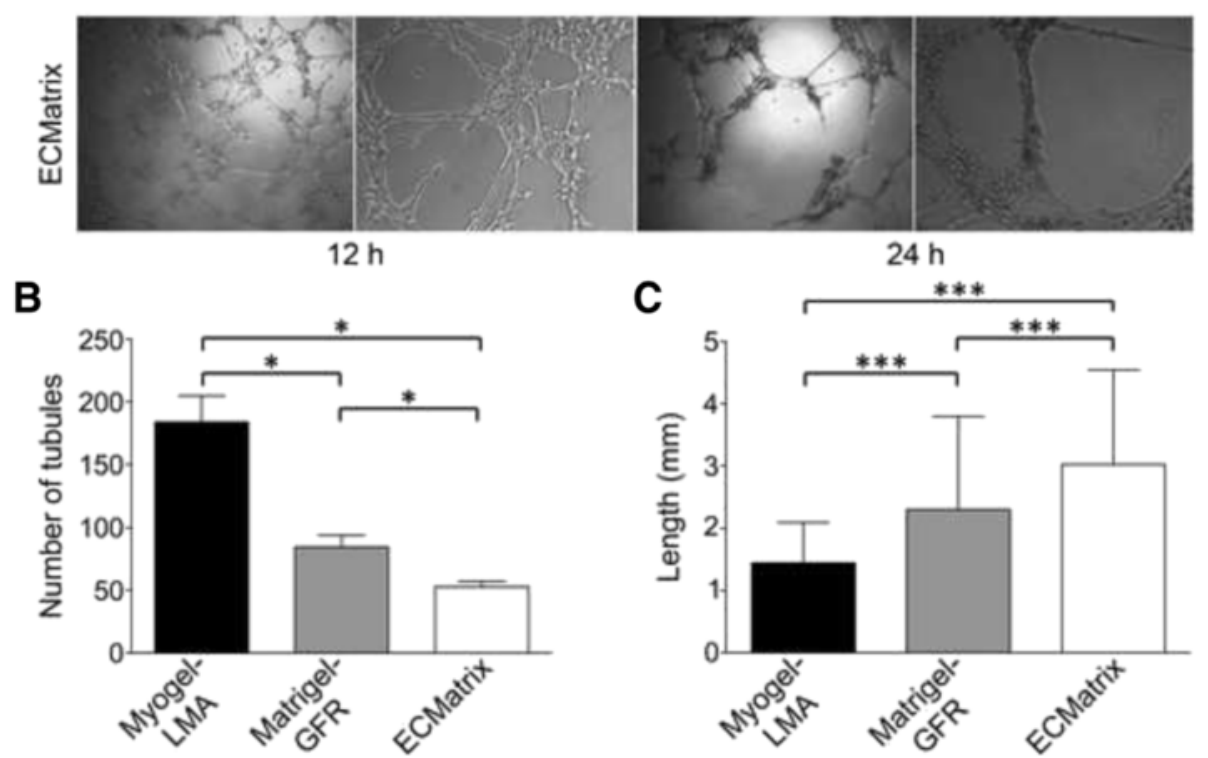

Fig. 6 In vitro capillary tube formation assay. Photomicrographs showing the typical appearance of tubules formed by HUVECs in the Myogel-LMA, Matrige ${ }^{\oplus}$-GFR and ECMatrix ${ }^{\mathrm{TM}}$ after 12, 24 and $72 \mathrm{~h}$ (only for Myogel-LMA) with the original magnifications of $4 \mathrm{x}$ and $10 \mathrm{x}$ (a). The number of tubules formed (b), and the diameter of the tubules formed (c) in each of the three matrices is shown. Three wells were coated for each coating and three visual fields per each well were analyzed, the average value per well was used for statistical analyses. Altogether nine wells were measured in triplicate. Error bars, mean \pm s.d., Mann-Whitney $U$ test, ${ }^{*} P<0.05$, *** $P<0.001$

normal human tissues or cultured cells. Since the composition of Myogel simulates well the TMEM of human solid cancers, it clearly offers improved characteristics also over mouse tumor matrix derivative Matrigel $^{\circledR}$ which is mouse EHS tumor-derived and has batch-to-batch variation. Myogel, used for coating cell culture wells, offered a matrix on which normal and transformed cells attached more efficiently than on BSA or plain plastic wells with PBS. It was beneficial also in vertical scratch assays. In addition, it was interesting to note that a Myogel coating affected the expression of 750 genes in HSC3 carcinoma cells compared to plain plastic, the method commonly used in RNA-microarray analyses. These genes were related to actin filament reorganization and contributed to cell motility providing some insight into the mechanisms behind the more intense migration of cancer cells on, through or in Myogel containing matrix in the experiments measuring cell movement. The factors in this G13 signaling pathway, such as WiskottAldrich syndrome-like (WASP), play important roles in cell response to extracellular stimuli by actin filament reorganization, and they are also known to contribute crucially to cancer cell motility [40]. Therefore, our results suggest that Myogel provides a more complex, natural human TMEM substrate for oncogenic assays than cell culture on plain plastic or even wells coated with individual molecules, such as collagen, fibronectin or vitronectin.

The mesenchymal fibroblasts (GFs and CAFs) remained viable when seeded on Myogel, but when embedded in a thick layer of Myogel-LMA they became apoptotic. 
However, carcinoma cells formed vital colonies even for up to 28 days. This indicates that Myogel, as a homogenous protein solution, cannot provide the collagenous fiber structures required for non-transformed cells, like fibroblasts, to survive. Instead, Myogel-LMA is ideal for soft agar -type assay commonly used to select normal from transformed cells [41]. Adding Myogel in agarose provides the cells a more natural TMEM, which most probably affects their growing potential. Here we saw a slight tendency of the carcinoma cells to form more large colonies in Myogel-LMA than in the plain LMA matrix. The hanging drop spheroids embedded in Myogel-LMA also seemed to grow more than the ones embedded in plain LMA.

The Transwell ${ }^{\circ}$ invasion assay, conducted classically by applying either Matrigel $^{\circ}$ or Matrigel $^{\circ}$-GFR to Transwell ${ }^{\circ}$ inserts [11], worked well with either Myogel or MyogelLMA. Interestingly, we were able to show that carcinoma cells invaded in Myogel even more efficiently than in Matrigel $^{\circ}$. Cancer cells also invaded through MyogelLMA mixtures more evenly throughout the whole membrane, whereas in Matrigel $^{\circ}$-mixtures the cells tended to invade in clumps. Myogel seems to offer an excellent, natural human TMEM, which helps to simulate the proper, natural interaction between TMEM and cancer cells. In our preliminary experiments we have also succeeded in using Myogel-LMA, instead of Matrigel ${ }^{\circ}$, in several chemotherapeutic and irradiation in vitro experiments (data not shown). Based on these experiments, we believe that Myogel-LMA is able to highly improve the quality of various preclinical human cancer studies.

For the study of tumor cell behavior, it is important to observe the cells under biological conditions since the cellular motility, form and growth in monolayer culture differ from that observed in 3D culture [42]. The hanging drop is a method of 3D cell culture, which mimics the environment of the cells within a tissue [43, 44]. This method is preferred compared to the other 3D cell culture settings since it allows the cells to form spheroids, in which cells are cultured in close contact to each other, making a small aggregated component. In hanging drop assay, spheroid is a form of an aggregated cluster of cells cultured in 3D physiological condition. The spheroids developed using the hanging drop method are widely used as a model for the study of cell-cell interactions [45], in vivo tumor tissue organization and microenvironment [46], and the melanoma reconstruction model [47]. In this study, we have optimized the method for the observation of single tumor cell motility in different matrices. When the speed of cell movement was compared between the matrices, the difference was clear: HSC-3 cells moved most rapidly in Myogelcollagen and their movement was the slowest in Matrigel $^{\circ}$-collagen.
We demonstrated that Myogel-LMA could also be applied to angiogenesis studies, where it represented a reliable way to produce and analyze data regarding vascular tube formation. In Myogel-LMA the number of tubes formed was higher but they were smaller in circumference compared to the other matrices. The vessel formation assay using Myogel-LMA could thus be suitable for pro- or anti-angiogenic drug assays where the number of tubes is the most critical factor to be evaluated. The differences between Matrigel ${ }^{\circ}$-GFR and ECMatrix $^{\mathrm{Tm}}$ assays could be explained by the fact that the levels of stimulatory cytokines and growth factors have been markedly reduced in the growth factor reduced Matrigel ${ }^{\circ}$ to avoid problems associated with the over-stimulation of endothelial cells. However, according to the manufacturer, ECMatrix $^{\mathrm{Tm}}$ is derived from EHS tumors and is similar to "normal" Matrigel ${ }^{\circ}$ and contains e.g. laminin, collagen type IV, heparan sulfate proteoglycans, entactin and nidogen. It also includes various growth factors (TGF- $\beta$, EFG) and proteolytic enzymes (plasminogen, tPA, MMPs) that should optimize it for maximal tubeformation. In all matrices, cellular network structures were fully developed by $12 \mathrm{~h}$, with the first signs apparent after 5-6 h. However, using Myogel-LMA, tube formation continued for as long as for $72 \mathrm{~h}$, whereas at that time the endothelial cells in Matrigel ${ }^{\circ}$-GFR and ECMatrix ${ }^{\mathrm{Tm}}$ were already in apoptosis.

\section{Conclusions}

In conclusion, Myogel, especially easy-to-use MyogelLMA, is well suited for in vitro cancer and angiogenesis studies. In some experiments Myogel is even superior to the Matrigel ${ }^{\circ}$, or rat tail type I collagen -based matrices. Using easily obtained, human uterus leiomyoma tissue to produce Myogel, production costs are relatively low. In addition, the use of myoma tissue is ethically superior to the sacrifice thousands of mice with EHS tumors required for the production of Matrigel ${ }^{\circ}$. Myogel together with the myoma disc organotypic model, could offer a natural human TMEM based kit to study various cancer cell lines, chemotherapy or irradiation effects in vitro. In theory, these materials may well be usable also in the future for personalized medicine. Myogel-LMA could facilitate the culture of cells from a fresh tumor tissue biopsy or a cell suspension and the effects of drugs or chemoradiation therapies tested to optimize the treatment for the patient.

\section{Availability of Data}

The microarray data reported in this paper have been deposited in the Gene Expression Omnibus (GEO) database, www.ncbi.nlm.nih.gov/geo (accession no. GSE68722). 


\section{Additional files}

Additional file 1: Figure S1. Gradient SDS-PAGE, 2-DE and zymography from Myogel and Matrige ${ }^{\oplus}$. Coomassie Blue stained gradient SDS-PAGE gel from four Myogel batches $(12,15-17)$ and their mixture and four

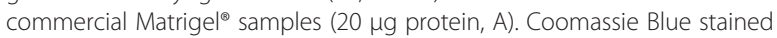
gradient SDS-PAGE gel from four Myogel samples (3, 4, 6 and 9) for Myogel proteomics by mass spectrometry $(10 \mu \mathrm{g}$ and $20 \mu \mathrm{g}$ protein, B). Silver 2D gels of Myogel (batches 16 and 17, $100 \mu \mathrm{g}$ protein) and Matrigel ${ }^{\circ}$ (100 and $300 \mu \mathrm{g}$ protein) samples (C). Gelatinolytic activities in Myogel and Matrige $\left.\right|^{\oplus}$ detected under long wave UV light by zymography. The empty lanes between the standard and Myogel-sample, Myogel- and Matrige $\left.\right|^{\oplus}$ samples and Matrigel ${ }^{\oplus}$-sample and control MMP-2 were deleted from the picture and these lanes are divided by white lines, control MMP-2 and -9 were initially in adjacent wells. (D). Gradient gel in A and zymography were run twice, gradient gel for proteomics and 2-DE gels once. Figure $\mathbf{S}$. Average speed of HSC-3 cell movement in hanging drops. HSC-3 cells were cultured in hanging drops in pure collagen, Myogel-collagen and Matrigel ${ }^{{ }^{-}}$ collagen matrices. Pictures were taken every $15 \mathrm{~min}$ for $20 \mathrm{~h}$ with a 40x objective. The hanging drop -assay was performed twice, but the analysis was performed from one experiment. (PDF $660 \mathrm{~kb}$ )

Additional file 2: Supplementary Method. The analysis of the cells in hanging drops. (PDF $591 \mathrm{~kb}$ )

Additional file 3: Table S1. Mass spectrometry results on myogel. (PDF $640 \mathrm{~kb}$ )

Additional file 4: Table S2. The pH-measurements of Myogel and Matrige ${ }^{\oplus}$. (PDF $111 \mathrm{~kb}$ )

Additional file 5: Table S3. Microarray results showing genes with FC 1.5 or more when the HSC-3 cells cultured on the top of plastic were compared to the corresponding cells grown on Myogel. (PDF $1329 \mathrm{~kb}$ )

Additional file 6: Movie S1. Nuclear stain, collagen.avi. Video showing cell movements in the hanging drop culture in pure collagen matrix tracked by nuclear stain. (AVI $4793 \mathrm{~kb}$ )

Additional file 7: Movie S2. Nuclear stain, Myogel-collagen.avi. Video showing cell movements in the hanging drop culture in Myogel-collagen matrix tracked by nuclear stain. (AVI $3832 \mathrm{~kb}$ )

Additional file 8: Movie S3. Nuclear stain, Matrigel-collagen.avi. Video showing cell movements in the hanging drop culture in Matrige ${ }^{{ }^{-}}$-collagen matrix tracked by nuclear stain. (AVI $4273 \mathrm{~kb}$ )

\section{Abbreviations}

2-DE: Two-dimensional gel electrophoresis; ATCC: American type culture collection; BSA: Bovine serum albumin; CAF: Carcinoma associated fibroblast; ECM: Extracellular matrix; EGF: Epidermal growth factor; EHS: EngelbrethHolm-Swarm; FBS: Fetal bovine serum; FC: Fold change; FDR: False discovery rate; FGF: Fibroblast growth factor; GEO: Gene expression omnibus; GF: Gingival fibroblast; GFP: Green fluorescent protein; GO: Gene ontology; H2B: Histone-2B; HUVEC: Human umbilical vein endothelial cell; IEF: Isoelectric focusing; LC: Liquid chromatography; LMA: Low melting agarose; MMP: Matrix metalloproteinase; MS: Mass spectrometry; MyogelLMA: Myogel mixed with low-melting agarose; PBS: Phosphate-buffered saline; PDGF: Platelet-derived growth factor; TCA: Trichloroacetic acid; TGF-a: Transforming growth factor alpha; TGF-ß3: Transforming growth factor beta; TME: Tumor microenvironment; TMEM: Tumor microenvironment matrix; tPA: Tissue plasminogen activator; TUNEL: Terminal deoxynucleotidyl transferase dUTP nick end labeling; WASP: Wiskott-Aldrich syndrome-like.

\section{Competing interests}

The authors (TS, MeSu, ES and FS) have filed a patent on Myogel.

\section{Authors' contributions}

TS conceived the project, planned the experiments, interpreted data and wrote the manuscript. MeSu planned and performed experiments, analyzed and interpreted data and wrote the manuscript. EHA, ES, NKC, CEdO, SUA, SO, FS, PJ, PÅ, CCB and JK planned and performed experiments, analyzed and interpreted data. MaSa and KS were responsible for myoma collection and LE, AFPL and RDC supervised experiments and interpreted data. All authors revised the manuscript.

\section{Authors' information}

Current affiliation for FS: Research Programs Unit - Molecular Neurology, and Institute of Biomedicine, Biomedicum Helsinki, University of Helsinki, Helsinki, Finland.

\section{Acknowledgements}

Mrs Maija-Leena Lehtonen and Mrs Eeva-Maija Kiljander are acknowledged for their excellent technical help in the experiments. We thank Dr Sami Yokoo, Dr Bianca Alves Pauletti and Dr Romênia R. Domingues, Laboratório Nacional de Biociências, LNBio, CNPEM, Campinas, Brazil, for their valuable help and advice with the laboratory work for mass spectrometry and analyzing the results. We acknowledge Dr. Cindy E. Dieteren, Department of Cell Biology, Radboud UMC, Netherlands, for providing the H2B-coupled mCherry expression vector. We thank the Biocenter Oulu Virus Core laboratory for providing help and the facilities for the work with lentiviral particles and the Biocenter Oulu DNA sequencing and expression analysis center for performing microarray analyses and training and help in their data analysis. We acknowledge the personnel of the Department of Obstetrics and Gynecology from the Oulu University Hospital for contributing to the research by providing the leiomyoma tissue. This work was supported by the Science without Borders (CAPES Program, Project 109/2012, AUXPE-PVES 570/2013) linked to the Special Visiting Researcher Program and grants from the Sigrid Juselius Foundation, Finnish Cancer Foundation, and Finnish Cultural Foundation and research funds from the Medical Faculty of the University of Oulu and Oulu University Hospital special state support for research and Medical Research Center Oulu.

\section{Author details}

${ }^{1}$ Cancer and Translational Medicine Research Unit, Faculty of Medicine, University of Oulu, PO Box 5281FI-90014 Oulu, Finland. ${ }^{2}$ Medical Research Center Oulu, Oulu University Hospital and University of Oulu, FI-90014 Oulu, Finland. ${ }^{3}$ Department of Oral and Maxillofacial Diseases, University of Helsinki, $\mathrm{Fl}-00014$ Helsinki, Finland. ${ }^{4} \mathrm{Clinical}$ Department, Faculty of Medicine of Jundiai (FMJ), Jundiai, São Paulo SP-13202-550, Brazil. ${ }^{5}$ Department of Oral Diagnosis, Oral Pathology Division, Piracicaba Dental School, University of Campinas, Piracicaba, São Paulo SP-13414-903, Brazil. ${ }^{6}$ Center for Machine Vision Research, University of Oulu, Fl-90014 Oulu, Finland. 'Biocenter Oulu, University of Oulu, Fl-90014 Oulu, Finland. ${ }^{8}$ Faculty of Biochemistry and Molecular Medicine, University of Oulu, Fl-90014 Oulu, Finland. ${ }^{9}$ Proteomics Core Facility, Biocenter Oulu, University of Oulu, Fl-90014 Oulu, Finland. ${ }^{10}$ Department of Obstetrics and Gynecology, Oulu University Hospital and University of Oulu, Fl-90029 Oulu, Finland. ${ }^{11}$ Department of Obstetrics and Gynecology, Tampere University Hospital and University of Tampere, Fl-33521 Tampere, Finland. ${ }^{12}$ Laboratório Nacional de Biociências, LNBio, CNPEM, Campinas SP-13083-970, Brazil.

Received: 1 July 2015 Accepted: 19 November 2015

Published online: 16 December 2015

\section{References}

1. Nurmenniemi S, Sinikumpu T, Alahuhta I, Salo S, Sutinen M, Santala M, et al. A novel organotypic model mimics the tumor microenvironment. Am J Pathol. 2009;175:1281-91.

2. Heinonen M, Hemmes A, Salmenkivi K, Abdelmohsen K, Vilén ST, Laakso M, et al. Role of RNA binding protein HuR in ductal carcinoma in situ of the breast. J Pathol. 2011;224:529-39.

3. Dayan D, Salo T, Salo S, Nyberg P, Nurmenniemi S, Costea DE, et al. Molecular crosstalk between cancer cells and tumor microenvironment components suggests potential targets for new therapeutic approaches in mobile tongue cancer. Cancer Med. 2012;1:128-40.

4. Bitu CC, Kauppila JH, Bufalino A, Nurmenniemi S, Teppo S, Keinänen M, et al. Cathepsin $\mathrm{K}$ is present in invasive oral tongue squamous cell carcinoma in vivo and in vitro. PLoS One. 2013;8:e70925.

5. Lee CL, Chiu PC, Hautala L, Salo T, Yeung WS, Stenman UH, et al. Human chorionic gonadotropin and its free $\beta$-subunit stimulate trophoblast invasion independent of LH/hCG receptor. Mol Cell Endocrinol. 2013;375: 43-52.

6. Agostini M, Almeida LY, Bastos DC, Ortega RM, Moreira FS, Seguin F, et al. The fatty acid synthase inhibitor orlistat reduces the growth and metastasis of orthotopic tongue oral squamous cell carcinomas. Mol Cancer Ther. 2014;13:585-95. 
7. Ahmed Haji Omar A, Korvala J, Haglund C, Virolainen S, Häyry V, Atula T, et al. Toll-like receptors -4 and -5 in oral and cutaneous squamous cell carcinomas. J Oral Pathol Med. 2015;44:258-65.

8. Teppo S, Sundquist E, Vered M, Holappa H, Parkkisenniemi J, Rinaldi T, et al. The hypoxic tumor microenvironment regulates invasion of aggressive oral carcinoma cells. Exp Cell Res. 2013;319:376-89.

9. Kibbey MC. Maintenance of the EHS sarcoma and Matrigel preparation. J Tissue Cult Methods. 1994;16:227-30.

10. Arnaoutova I, George J, Kleinman HK, Benton G. The endothelial cell tube formation assay on basement membrane turns 20: state of the science and the art. Angiogenesis. 2009;12:267-74.

11. Albini A, Noonan DM. The 'chemoinvasion' assay, 25 years and still going strong: the use of reconstituted basement membranes to study cell invasion and angiogenesis. Curr Opin Cell Biol. 2010;22:677-89.

12. Wolf $K$, Alexander $S$, Schacht $V$, Coussens LM, von Andrian UH, van Rheenen $J$, et al. Collagen-based cell migration models in vitro and in vivo. Semin Cell Dev Biol. 2009;20:931-41.

13. Fusenig NE, Breitkreutz D, Dzarlieva RT, Boukamp P, Bohnert A, Tilgen W. Growth and differentiation characteristics of transformed keratinocytes from mouse and human skin in vitro and in vivo. J Invest Dermatol. 1983;81:168-75.

14. Nyström ML, Thomas GJ, Stone M, Mackenzie IC, Hart IR, Marshall JF. Development of a quantitative method to analyse tumour cell invasion in organotypic culture. J Pathol. 2005;205:468-75.

15. Mao Y, Schwarzbauer JE. Stimulatory effects of a three-dimensional microenvironment on cell-mediated fibronectin fibrillogenesis. J Cell Sci. 2005;118:4427-36.

16. Ho W, Tawil B, Dunn JC, Wu BM. The behavior of human mesenchymal stem cells in 3D fibrin clots: dependence on fibrinogen concentration and clot structure. Tissue Eng. 2006:12:1587-95.

17. Gurski LA, Jha AK, Zhang C, Jia X, Farach-Carson MC. Hyaluronic acid-based hydrogels as 3D matrices for in vitro evaluation of chemotherapeutic drugs using poorly adherent prostate cancer cells. Biomaterials. 2009;30:6076-85.

18. Hynes RO. The extracellular matrix: not just pretty fibrils. Science. 2009;326: 1216-9.

19. Rakashanda S, Rana F, Rafiq S, Masood A, Amin S. Role of proteases in cancer: A review. Biotechnol Mol Biol Rev. 2012;7:90-101.

20. Hanahan D, Weinberg RA. Hallmarks of cancer: the next generation. Cell. 2011;144:646-74.

21. Abberton KM, Bortolotto SK, Woods AA, Findlay M, Morrison WA, Thompson EW, et al. Myogel, a novel, basement membrane-rich, extracellular matrix derived from skeletal muscle, is highly adipogenic in vivo and in vitro. Cells Tissues Organs. 2008;188:347-58.

22. Francis D, Abberton K, Thompson E, Daniell M. Myogel supports the ex-vivo amplification of corneal epithelial cells. Exp Eye Res. 2009:88:339-46.

23. Ting AC, Craft RO, Palmer JA, Gerrand YW, Penington AJ, Morrison WA, et al. The adipogenic potential of various extracellular matrices under the influence of an angiogenic growth factor combination in a mouse tissue engineering chamber. Acta Biomater. 2014;10:1907-18.

24. Yuan K, Kucik D, Singh RK, Listinsky CM, Listinsky JJ, Siegal GP. Alterations in human breast cancer adhesion-motility in response to changes in cell surface glycoproteins displaying alpha-L-fucose moieties. Int J Oncol. 2008; 32:797-807.

25. Hanna SL, Sherman NE, Kinter MT, Goldberg JB. Comparison of proteins expressed by Pseudomonas aeruginosa strains representing initial and chronic isolates from a cystic fibrosis patient: an analysis by 2-D gel electrophoresis and capillary column liquid chromatography-tandem mass spectrometry. Microbiology. 2000;146:2495-508.

26. Ohlmeier S, Vuolanto M, Toljamo T, Vuopala K, Salmenkivi K, Myllärniemi M et al. Proteomics of human lung tissue identifies surfactant protein $\mathrm{A}$ as a marker of chronic obstructive pulmonary disease. J Proteome Res. 2008;7: 5125-32.

27. Pirilä E, Korpi JT, Korkiamäki T, Jahkola T, Gutierrez-Fernandez A, Lopez-Otin C, et al. Collagenase-2 (MMP-8) and matrilysin-2 (MMP-26) expression in human wounds of different etiologies. Wound Repair Regen. 2007;15:47-57.

28. Coletta RD, Almeida OP, Graner E, Page RC, Bozzo L. Differential proliferation of fibroblasts cultured from hereditary gingival fibromatosis and normal gingiva. J Periodontal Res. 1998:33:469-75.

29. Seguin F, Carvalho MA, Bastos DC, Agostini M, Zecchin KG, Alvarez-Flores MP, et al. The fatty acid synthase inhibitor orlistat reduces experimental metastases and angiogenesis in B16-F10 melanomas. Br J Cancer. 2012;107: 977-87.
30. Del Duca D, Werbowetski T, Del Maestro RF. Spheroid preparation from hanging drops: characterization of a model of brain tumor invasion. J Neurooncol. 2004;67:295-303.

31. Li C, Wong WH. Model-based analysis of oligonucleotide arrays: expression index computation and outlier detection. Proc Natl Acad Sci U S A. 2001;98:31-6.

32. Vukicevic S, Kleinman HK, Luyten FP, Roberts AB, Roche NS, Reddi AH. Identification of multiple active growth factors in basement membrane Matrigel suggests caution in interpretation of cellular activity related to extracellular matrix components. Exp Cell Res. 1992;202:1-8.

33. Hughes CS, Postovit LM, Lajoie GA. Matrigel: a complex protein mixture required for optimal growth of cell culture. Proteomics. 2010;10:1886-90.

34. Talbot NC, Caperna TJ. Proteome array identification of bioactive soluble proteins/peptides in Matrigel: relevance to stem cell responses. Cytotechnology. 2015;67:873-83.

35. Mackay AR, Gomez DE, Cottam DW, Rees RC, Nason AM, Thorgeirsson UP. Identification of the 72-kDa (MMP-2) and 92-kDa (MMP-9) gelatinase/type IV collagenase in preparations of laminin and Matrigel. Biotechniques. 1993;15: 1048-51.

36. Yip D, Cho CH. A multicellular 3D heterospheroid model of liver tumor and stromal cells in collagen gel for anti-cancer drug testing. Biochem Biophys Res Commun. 2013:433:327-32.

37. Donovan D, Brown NJ, Bishop ET, Lewis CE. Comparison of three in vitro human 'angiogenesis' assays with capillaries formed in vivo. Angiogenesis. 2001;4:113-21.

38. Mehine M, Kaasinen E, Aaltonen LA. Chromothripsis in uterine leiomyomas. N Engl J Med. 2013;369:2160-1.

39. Mehine M, Mäkinen N, Heinonen HR, Aaltonen LA, Vahteristo P. Genomics of uterine leiomyomas: insights from high-throughput sequencing. Fertil Steril. 2014;102:621-9.

40. Takenawa T, Miki H. WASP and WAVE family proteins: key molecules for rapid rearrangement of cortical actin filaments and cell movement. J Cell Sci. 2001;114:1801-9.

41. Agrez MV, Kovach JS, Lieber MM. Cell aggregates in the soft agar "human tumour stem-cell assay". Br J Cancer. 1982;46:880-7.

42. Elsdale T, Bard J. Collagen substrata for studies on cell behavior. J Cell Biol. 1972;54:626-37.

43. Foty R. A simple hanging drop cell culture protocol for generation of $3 \mathrm{D}$ spheroids. J Vis Exp. 2011;e2720. doi: 10.3791/2720.

44. Weiswald LB, Bellet D, Dangles-Marie V. Spherical cancer models in tumor biology. Neoplasia. 2015;17:1-15.

45. Amann A, Zwierzina M, Gamerith G, Bitsche M, Huber JM, Vogel GF, et al. Development of an innovative 3D cell culture system to study tumour-stroma interactions in non-small cell lung cancer cells. PLoS One. 2014;9:e92511.

46. Wong C, Vosburgh E, Levine AJ, Cong L, Xu EY. Human neuroendocrine tumor cell lines as a three-dimensional model for the study of human neuroendocrine tumor therapy. J Vis Exp. 2012;e4218. doi: 10.3791/4218.

47. Vörsmann H, Groeber F, Walles H, Busch S, Beissert S, Walczak H, et al. Development of a human three-dimensional organotypic skin-melanoma spheroid model for in vitro drug testing. Cell Death Dis. 2013;4:e719.

\section{Submit your next manuscript to BioMed Central and we will help you at every step:}

- We accept pre-submission inquiries

- Our selector tool helps you to find the most relevant journal

- We provide round the clock customer support

- Convenient online submission

- Thorough peer review

- Inclusion in PubMed and all major indexing services

- Maximum visibility for your research

Submit your manuscript at www.biomedcentral.com/submit 